\title{
Investigations into manufacturing composite profiles having local magnesium-foam reinforcements
}

\author{
Tillmann Plorin ${ }^{1, a}$, Dirk Bormann ${ }^{1, b}$, Torsten Heidenblut ${ }^{1, c}$, \\ Friedrich-Wilhelm Bach ${ }^{1, d}$ \\ ${ }^{1}$ Institute of Materials Science (IW), Leibniz Universität Hannover (LUH), \\ An der Universität 2, 30823 Garbsen, Germany
}

aplorin@iw.uni-hannover.de, bbormann@iw.uni-hannover.de, cheidenblut@iw.uni-hannover.de, doffice@iw.uni-hannover.de

Keywords: magnesium foam, reinforced foam, roll forming

\begin{abstract}
Owing to their mechanical properties, metallic foams possess the outstanding ability to considerably improve a structure's stiffness and energy absorption capacity with low increases in weight. In the research results from the sub project A4 "Foam filled, rolled, closed profiles" of the CRC 675 "Creation of high strength metallic structures and joints by setting up scaled local material properties" introduced here, both the manufacture as well as the reinforcement of magnesium foams, which are produced by means of powder metallurgy, are described. The potential for increasing their strengths using reinforcements are demonstrated and the results of mechanical tests are presented. In addition to this, research results are presented which have contributed to achieving the main objectives of developing a combined technology for producing profiles which are locally reinforced using magnesium foam. The developed technology is characterised by integrating the foaming process into the roll forming process.
\end{abstract}

\section{Introduction}

In many areas of modern industry, above all in automotive and mechanical engineering as well as in architecture and design, demands for new materials and innovative material concepts are expressed due to the continually increasing component requirements regarding loading capacity and complexity. A particular challenge for today's materials scientists is to specifically increase the degree of lightweight construction whilst maintaining the same or improving the safety and comfort characteristics or enhancing the integration of its functions. Here, according to the application and industry, different trends can be clearly discerned which often agree that a promising future role is attributed to composite technology and to a material mix in the form of hybrid material composites.

In profiled lightweight structures for frames and load-bearing elements, lightweight structural concepts based on constructional, manufacturing and, above all, materials technologies are still required, particularly when, besides purely stiffness requirements, additional functions such as vibrational damping or crash absorption via adequate plasticity are needed. In this case, the concept of component-reinforcement using metallic foams can be persuasive.

Metal foams possess outstanding mass-stiffness ratios since they distribute their low weight over a large volume. They have excellent properties for absorbing acoustic and vibrational loads and exhibit a higher thermal stability in comparison to polymer foams. Apart from their low densities, in the range $0.3-0.8 \mathrm{~g} / \mathrm{cm}^{3}$, the ability to reduce their volume under compressive load, and thereby to absorb energy, should be particularly emphasised. Due to their properties, metallic foams which are primarily integrated into structures such as sandwich and profile-composites are investigated and employed. This combination of lightweight material and structural design can be particularly relevant in applications for reinforcing and energy absorption in automotive engineering [1] as well as for stiffening and noise reduction in mechanical engineering [2]. An overview of their manufacture and further applications can be found in, e.g. [3]. 
Top-hat and tubular profiles in particular, which are reinforced using metallic foams, demonstrate outstanding properties which are ideally suited for applications as crash absorbers. Besides the experimental work, contributions for predicting the properties using numerical methods can, to a large extent, also be found here, e.g. [4,5]. Furthermore, by employing metallic foams as reinforcing elements for hollow profiles, undesirable wall-vibrations can be reduced, especially for thin-walled profiles. However, on implementing them for extremely lightweight structures, it has to be pointed out that the completely foam-filled profiles can not necessarily realise a weight advantage over increasing the wall thickness. Furthermore, when it is considered that loads often only operate at very limited locations, then simple, partially executed foam-filling is sought to locally raise the buckling and denting stiffness of hollow profiles. Studies on local stiffening of hollow structures in [6], such as for example crash struts for side-on collision protection, shown that local stiffening can have a specific influence on the mechanical behaviour.

In the project presented here within the framework of the CRC 675 "High Strength Structures", the development of a combined technology is further investigated for manufacturing hollow profiles based on steel, aluminium and especially magnesium which are locally reinforced using magnesium foam. This technology is characterised by integrating the foaming and roll forming processes such that partially foamed hollow profiles are to be manufactured in a continuous profiling operation so that the time-consuming joining process for securing the local foam-elements can be dispensed with. The end-product is a partially foamed structure which is adapted to the loading profile and can be manufactured according to individual designs. This also includes developing measures for increasing the strength of the magnesium foam itself. Since the foams possess only low tensile, torsional and impact strengths, the composite structure must be designed such that the foam does not fail.

\section{Manufacture of magnesium foams by means of powder metallurgy}

A current overview of the state of research into cellular metals is given, for example by [7,8]. From the perspective of conventional, powder and fusion metallurgical manufacturing of foams, aluminium still dominates and is the most widespread in research and industry. The manufacturing technologies, properties, different processing methods as well as testing methods and possible applications are summarised in [9]. The developments of the last few years have significantly contributed to broadening the flexibility of foam production. Using the Advanced Pore Morphology (APM) technology, individual foam pellets can be adhesively bonded into an entire component by means of separating the foam expansion from component shaping [10,11]. The foamable bulk material PolyFom is used to economically form the foam parts by means of improved charging and automation [12].

The manufacture of magnesium foam is still only implemented in a few research establishments. The manufacture of magnesium foam by means of fusion metallurgy is described in [13]. Here, the foaming agent $\left(\mathrm{TiH}_{2}\right)$ is added to an $\mathrm{AZ91}$ melt. Both foaming at $650{ }^{\circ} \mathrm{C}$ as well as the subsequent cooling occurs in an argon atmosphere. Enhancing the $\mathrm{Mg}$ integral foam-manufacturing by using low-pressure thixo die casting is described in [14,15]. Currently, the powder metallurgical method has only been realised at the Institute of Materials Science in Hannover and is schematically depicted in Fig. 1. 
Magnesium and titanium hydride powders are employed as the initial material, which are homogeneously mixed and subsequently pressed, in multiple stages, into foamable precursor material. The foam formation is initiated by heating the foamable precursors to above magnesium's melting point. A downstream cooling section halts this process. The foaming behaviour could be significantly improved by adding and pressing a supplement of zinc powder. Diffusion of zinc into the magnesium matrix was achieved in a heat-treatment following the injection procedure. The diffusion of magnesium takes place significantly slower so that, according to the Kirkendall-Effect, voids collect in place of the previously present zinc particles and hence pores already exist in the foamable precursor before the foaming begins. The existing pores in the foamable precursor relieve the pressure of the hydrogen gas released by the decomposition of titanium hydride. The hydrogen has already separated at lower temperatures than the melting point of magnesium $\mathrm{T}_{\mathrm{L}}=650{ }^{\circ} \mathrm{C}$. Furthermore, the growth of cracks, which form in the foamable precursor material during the initial phase of the foaming, is halted by of the existing pores. This leads to a homogenous pore distribution in the resulting foam. The magnesium foams manufactured using this method exhibit a homogeneous pore structure and are manufactured with a density of approx. 0.3 to $0.7 \mathrm{~g} / \mathrm{cm}^{3}$.

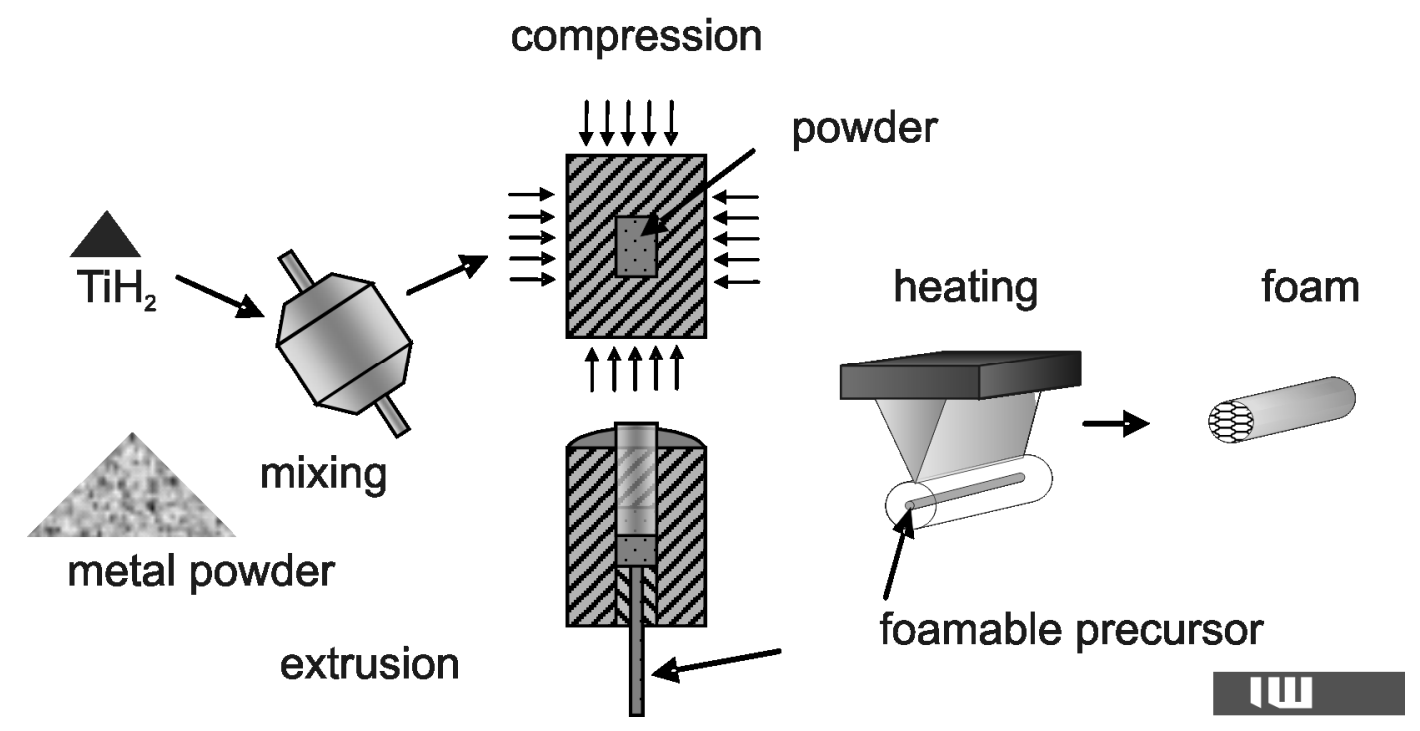

Fig. 1: Schematic of the powder metallurgical foaming of magnesium 
Influence of the magnesium powder's particle size. Tests with different particle sizes of magnesium powder $(<45 \mu \mathrm{m},<75 \mu \mathrm{m}, 100-250 \mu \mathrm{m}$ as well as150-400 $\mu \mathrm{m})$ have shown that higher foam quality can be obtained with decreasing initial powder sizes. Fig. 2 and Fig. 3 show computer tomographic analyses of two MgZn3-foams which were produced from different initial Mg-powder sizes.

\section{Mg particle size $<75 \mu \mathrm{m}$}
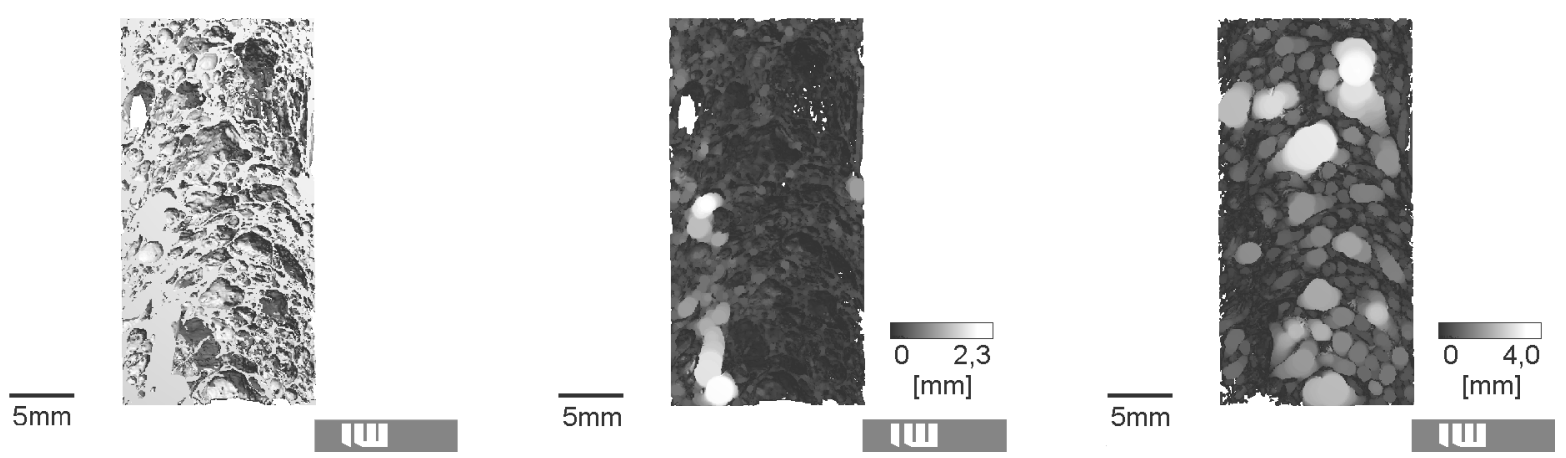

Fig. 2: Influence of the magnesium powder's particle size on the foam's structure: Computer tomographic (CT) -analysis of a MgZn3-foam produced from Mg-powder <75 $\mu \mathrm{m}$, crosssection (left), web-thickness analysis (centre), pore-size analysis (right)

The evaluation of the computer tomographic analysis shows that the foam produced from $\mathrm{Mg}$ powder $<75 \mu \mathrm{m}$ possesses an inhomogeneous distribution of both the web-thicknesses as well as the pore sizes. This can not be discerned in foams produced from Mg-powder having particle sizes $<45 \mu \mathrm{m}$, see Fig. 3. Here, both the web-thickness analysis as well as the pore sizes exhibit uniform distributions.

\section{Mg particle size $<45 \mu \mathrm{m}$}
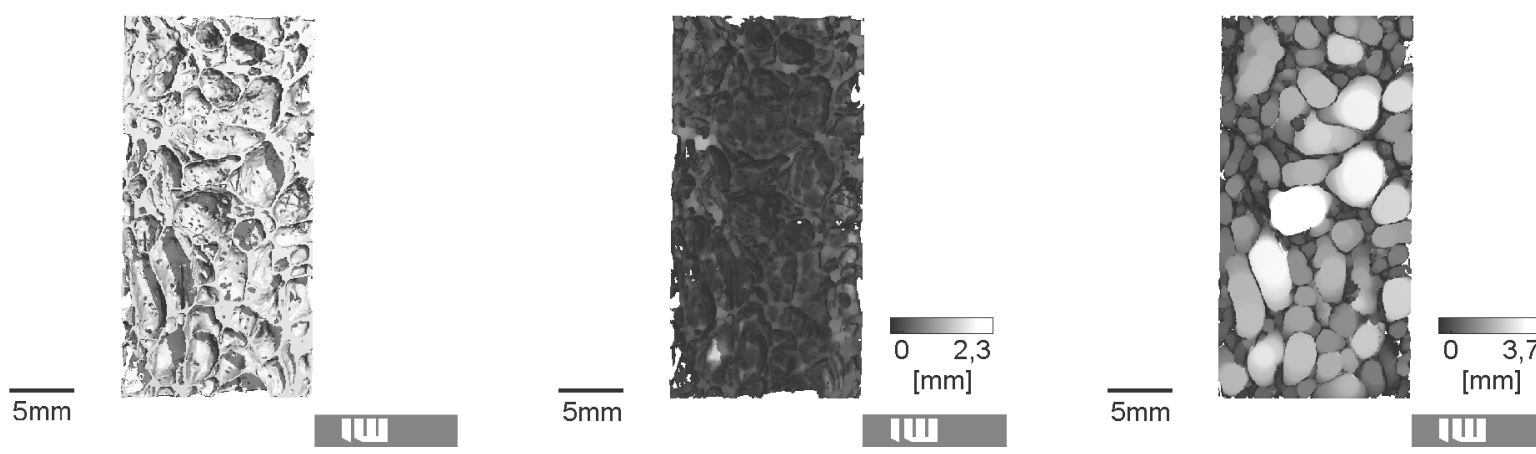

ताI

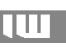

Fig. 3: Influence of the magnesium powder's particle size on the foam's structure: Computer tomographic (CT) -analysis of a MgZn3-foam produced from Mg-powder $<45 \mu \mathrm{m}$, crosssection (left), web-thickness analysis (middle), pore-size analysis (right) 
The graphical evaluation of both foams' pore-size distributions also clarifies this. It was possible to obtain an improved trend towards a normal distribution by using particle sizes $<45 \mu \mathrm{m}$; see Fig. 4 .

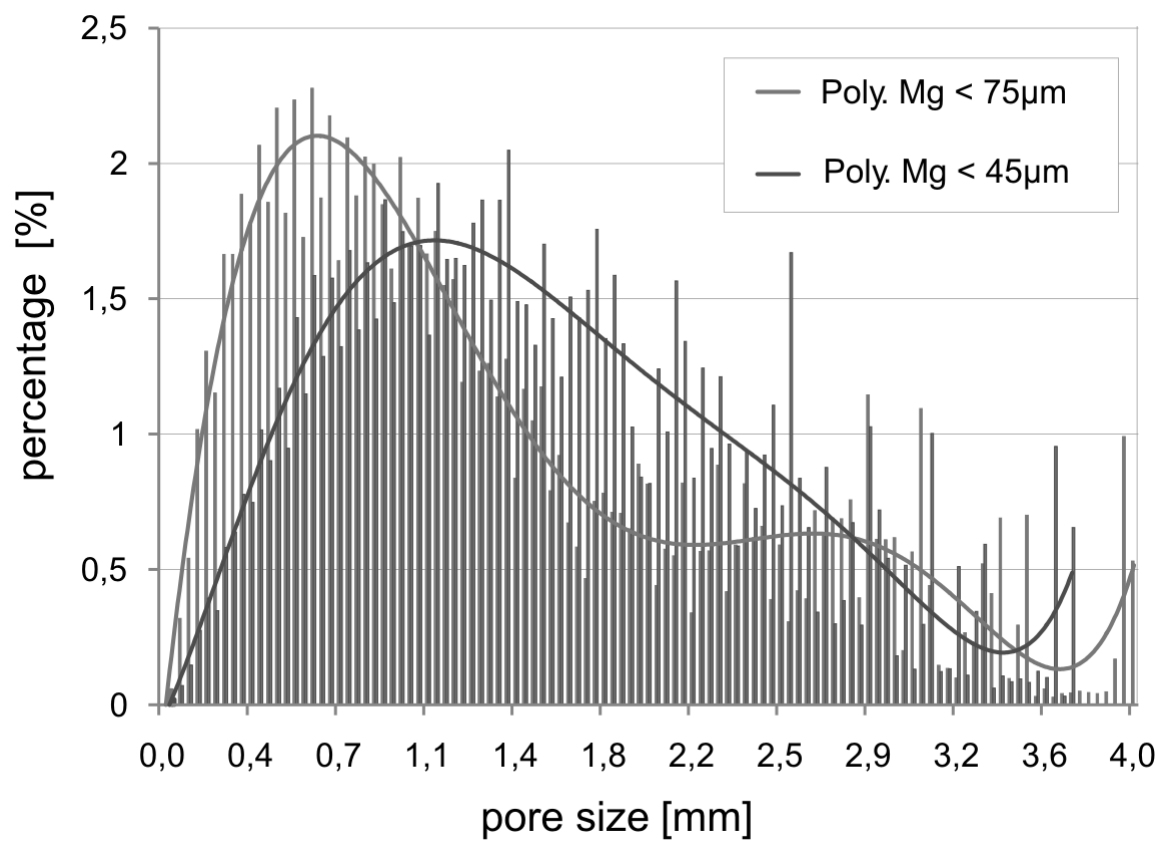

Fig. 4: Graphical depiction of the pore size distribution of $\mathrm{MgZn} 3$ foams, produced from different initial Mg powder sizes

The manufacture and properties of foamable precursor material. The manufacture of foamable $\mathrm{Mg}$ precursor material is carried out using a powder metallurgical method such as that described in detailed in [16]. In the initial phase of this project, the powder blend was pre-compacted and the powder billets $(\varnothing 30 \mathrm{~mm}$, length $90 \mathrm{~mm}$ ) were subsequent extruded using the Institute's own $800 \mathrm{kN}$ laboratory extruder.

It was possible to realise a clear improvement in quality of the foamable precursors, particularly with regard to their homogeneity and degree of compaction, by means of both analysing the influence of the initial powder sizes as well as compacting the powder blend using cold isostatic pressing (CIP). Here, the geometry of the pre-compacted powder billets $(\varnothing 100 \mathrm{~mm}$, length $300 \mathrm{~mm}$, weight approx. $4 \mathrm{~kg}$ ) was selected such that it is also possible to carry out further processing by using the Institute's own $10 \mathrm{MN}$ extruder (SMS Meer).

Both alloy forming and inert powders are added to the magnesium powder in order to regulate different effects which serve to improve the foam quality. By adding zinc, the primary pore formation described above can be obtained. Moreover, in combination with zinc, the suitability of tin, silicon and silicon carbide was tested. Tin forms high melting-point phases with magnesium, with whose aid the smelt's viscosity was to be raised in order to exert an influence on the foam's stability and ultimately on the mould-filling too. The same applies to the addition of silicon and silicon carbide. Here however, the high melting-point phases are directly added.

In order to verify the homogeneity of the manufactured CIP powder billets, specimens were taken each from the centre and from the flanks of the billets and were examined using both metallographically prepared samples as well as distribution images of the EDX analyser; an example of which is shown in Fig. 5 below. 

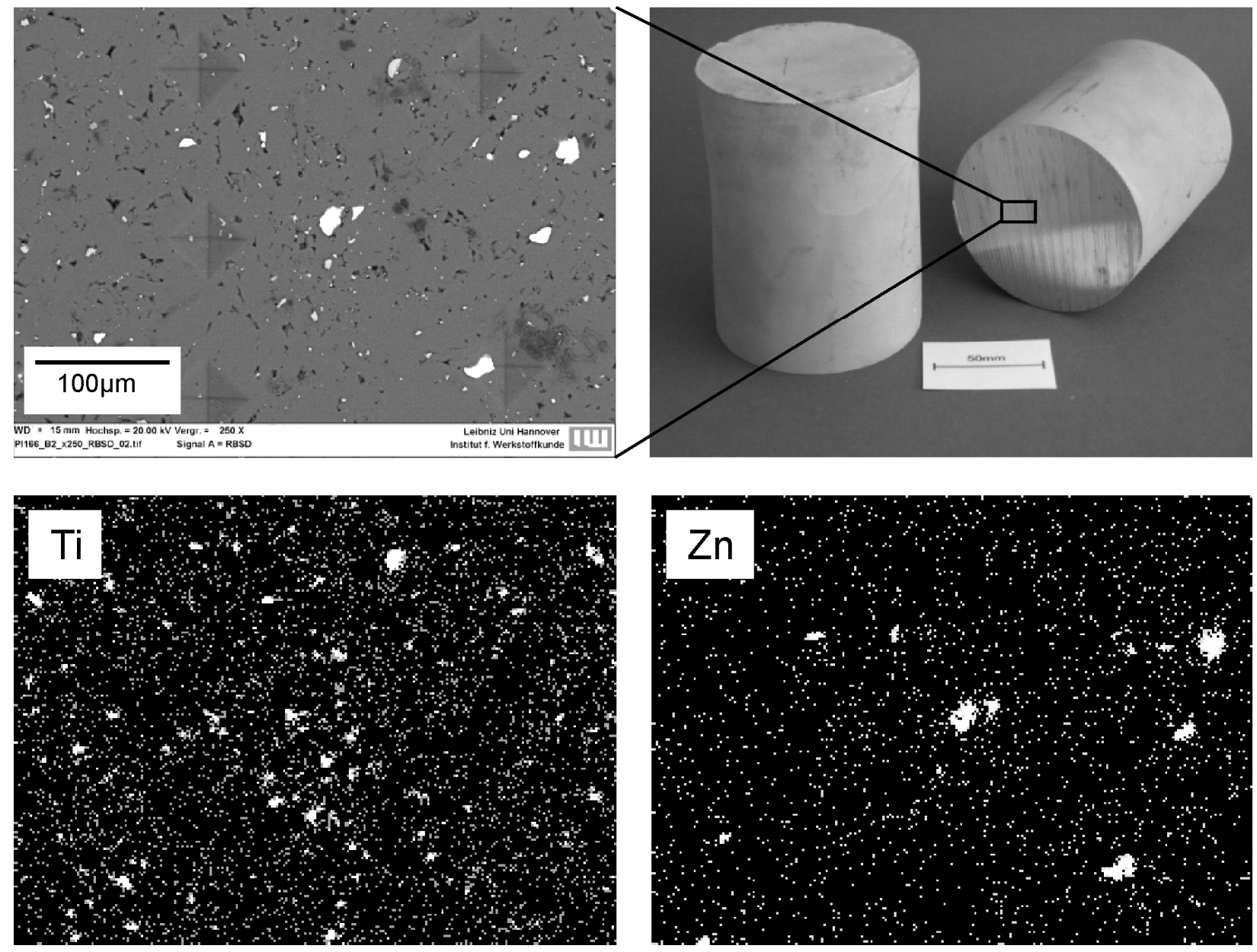

Fig. 5: Analysis of the composition in CIP compacted billets $(\varnothing 100 \mathrm{~mm}$, length $300 \mathrm{~mm})$ by means of EDX distribution images (here, at the cross-section from the billet's centre)

To identify the optimum CIP parameters, powder blends were compacted into pressed billets at three different pressures and subsequently extruded into foamable precursor material (wire) having a diameter $d=5 \mathrm{~mm}$ using an extrusion ratio of 156.25. As an illustration, Fig. 6 shows extrusion remnants with protruding wires.

However, on processing the powder blends compacted at 800 bar, an unsatisfactory surface finish having deep cracks was revealed; see Fig. 7, left. A compaction pressure of 1500 bar and an edgeradiusing on the extrusion die turned out to produce optimum results; see Fig. 7, right. A further increase in the CIP compaction pressure from 1500 bar to 2000 bar ultimately entailed an inferior compactability. For this reason, a pre-compaction of 1500 bar was chosen for all further foamable precursor material. The billets produced in this way possess a density which corresponds to $92 \%$ of that for bulk magnesium. 


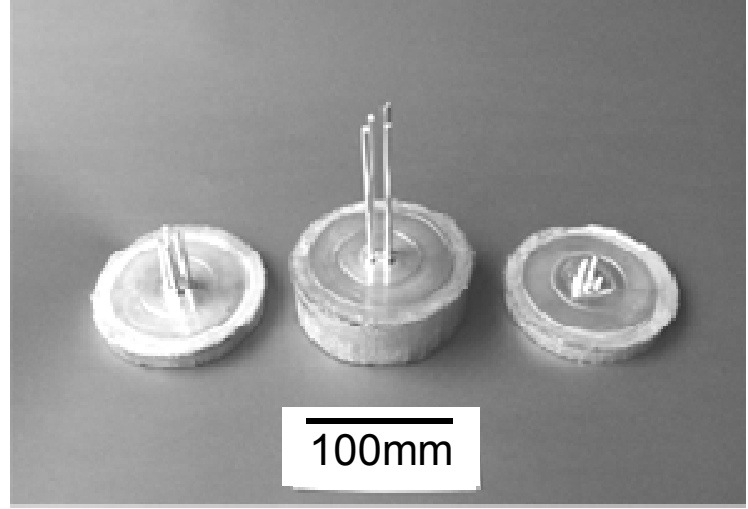

Fig. 6: Extrusion remnants from the manufacture of $\varnothing 5 \mathrm{~mm}$ foamable precursor material, extrusion ratio $=156.25$

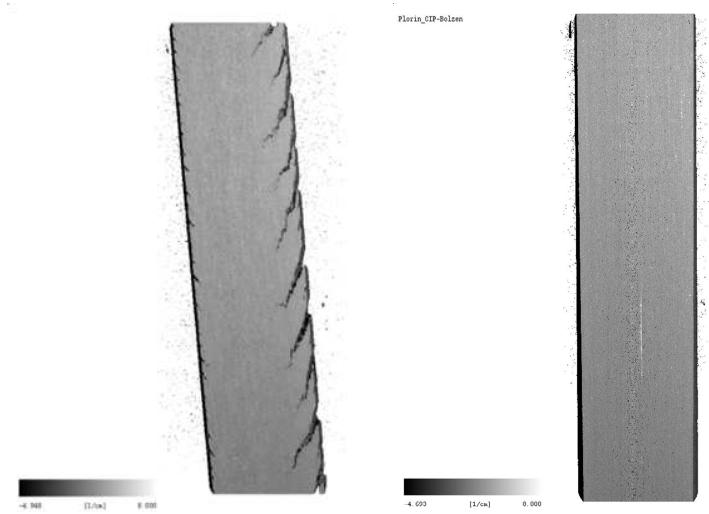

Fig. 7: CT section images of $\varnothing 5 \mathrm{~mm}$ foamable precursor material; left, having surface cracks, pre-compacted at 800 bar and right, without cracks, pre-compacted at 1500 bar

Table 1 shows the compositions of the $(\varnothing 5 \mathrm{~mm})$ foamable precursors used within the framework of this research project.

Table 1: Overview of the powder blends' compositions used here

\begin{tabular}{|c|c|c|c|c|c|c|}
\hline & $\mathrm{Mg}<45 \mu \mathrm{m}$ & $\begin{array}{c}\mathrm{Zn} \\
<45 \mu \mathrm{m}\end{array}$ & $\begin{array}{c}\text { Sn } \\
<45 \mu m\end{array}$ & $\begin{array}{c}\mathbf{S i} \\
<45 \mu \mathrm{m}\end{array}$ & $\begin{array}{c}\mathrm{SiC} \\
<150 \mu \mathrm{m}\end{array}$ & $\begin{array}{r}\mathrm{TiH}_{2} \\
<1,8 \mu \mathrm{m}\end{array}$ \\
\hline Alloy No. & wt-\% & wt-\% & wt-\% & wt-\% & wt-\% & wt-\% \\
\hline 1 & 95.5 & 3.0 & & & & 1.5 \\
\hline 2 & 92.5 & 6.0 & & & & 1.5 \\
\hline 3 & 95.5 & & 3.0 & & & 1.5 \\
\hline 4 & 94.0 & 3.0 & 1.5 & & & 1.5 \\
\hline 5 & 92.5 & 3.0 & 3.0 & & & 1.5 \\
\hline 6 & 92.5 & 3.0 & & 3.0 & & 1.5 \\
\hline 7 & 90.5 & 3.0 & & & 5.0 & 1.5 \\
\hline
\end{tabular}

The examinations of the extruded foamable precursor material were also initially carried out by means of metallographic samples. The alloy composition was verified using the quantitative EDX analysis (energy dispersive x-ray analysis). As an example, Fig. 8 shows the analysis for alloy No. 6 $\left(\mathrm{MgZn} 3 \mathrm{Si} 3+1.5 \mathrm{TiH}_{2}\right)$ from Table 1 . 


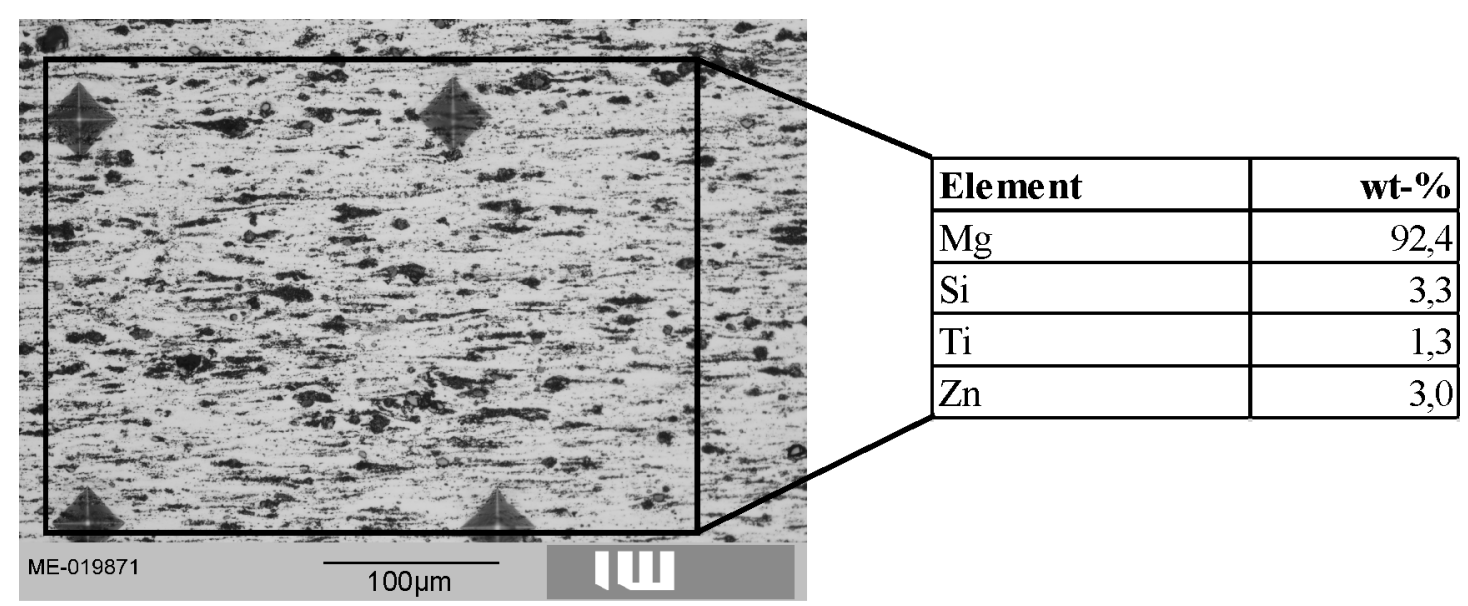

Fig. 8: Selected longitudinal micrograph, foamable precursor of $\mathrm{MgZn} 3 \mathrm{Si3}+1.5 \mathrm{TiH}_{2}$, extruded at $\mathrm{T}=300{ }^{\circ} \mathrm{C}$, heat treated for $2 \mathrm{~h}$ at $320^{\circ} \mathrm{C}$, together with quantitative evaluation of the alloy's composition (EDX analysis, right)

It is particularly important that the alloy's and the foaming agent's powder is homogeneously distributed: This could be successfully demonstrated for all alloys subsequent to extrusion, see for example Fig. 9. This is important for two reasons; firstly for a homogeneous distribution of pores in the metal foam and secondly, that the molten foam is to be stabilised via the alloy's powder.
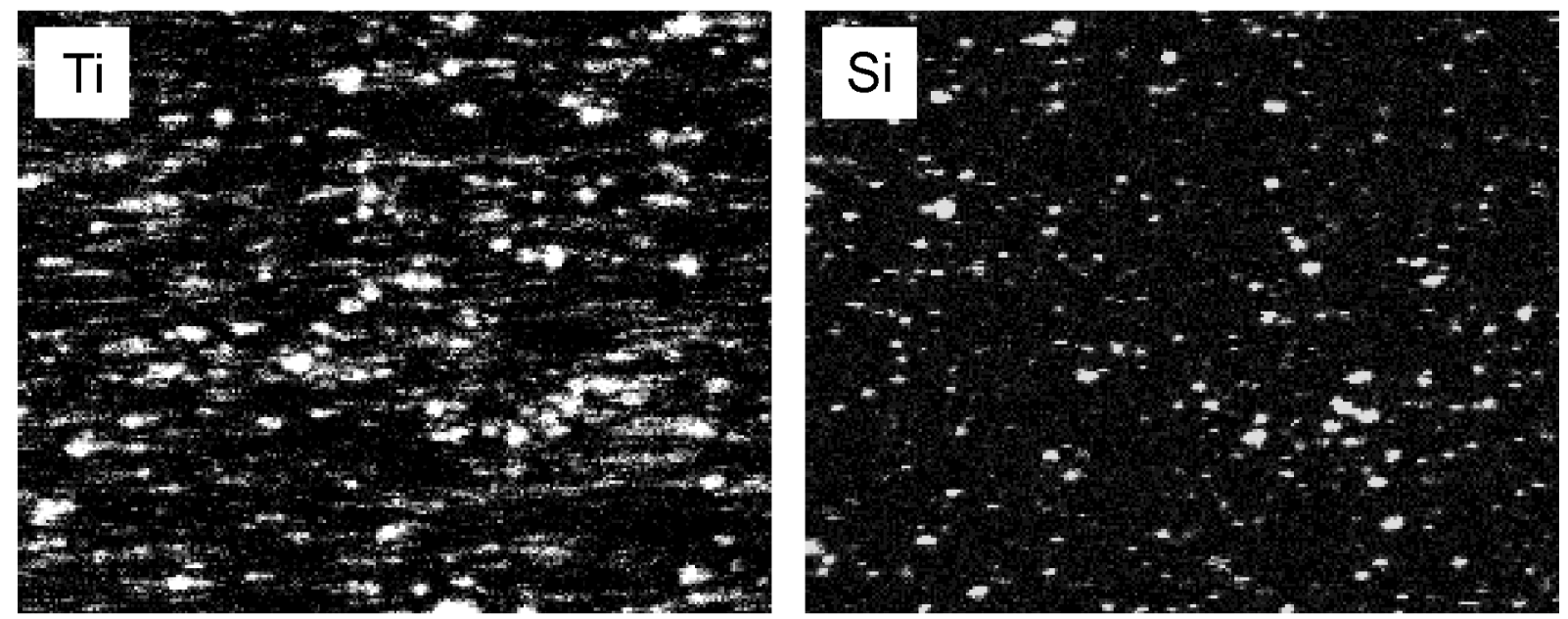

Fig. 9: Distribution images for titanium (left) and silicon (right) in the foamable precursor $\left(\mathrm{MgZn} 3 \mathrm{Si3}+1.5 \mathrm{TiH}_{2}\right.$, extruded at $\mathrm{T}=300{ }^{\circ} \mathrm{C}$, heat treated for $2 \mathrm{~h}$ at $\left.320^{\circ} \mathrm{C}\right)$ from Fig. 8

The increased foam stabilisation, which was demonstrated in the preliminary tests e.g. [17], and foam homogeneity obtained by using heat treated $\mathrm{Mg}$ - $\mathrm{Zn}$ alloys as the foamable precursor can be attributed to the diffusion of the zinc into the Mg-matrix. This effect could also be set for the manufactured foamable precursor by heat treating for $2 \mathrm{~h}$ at $320^{\circ} \mathrm{C}$.

A short process time for introducing the foam is sought for integrating the foaming process into a continuous roll forming process. The foaming time was determined to set initial limits on the necessary process times and to gain knowledge about the influencing parameters such as alloy composition and heat treatment. The foaming time (time to maximum expansion) was recorded by means of $100 \mathrm{~mm}$ long foamable precursors which were heated on one side using a $2 \mathrm{~kW}$ lineal, infrared emitter. The heat input was interrupted as soon as the foam expansion stopped or even when the foam began to collapse.

The mean values of the foaming times recorded in this way for all the alloys $(3$ specimens per alloy) are depicted in the below, see Fig. 10. 
It can be discerned that no significant increase or decrease in times occur either for different alloys or for post heat-treatments so that an average foaming time of $\mathrm{t}=60 \mathrm{~s}$ can be assumed at maximum emitter power. Consequently, the heat transfer can be designated as the foaming time's determining factor and not the change in the foamable precursors thermal conductivity or the lowering of the liquidus temperature.

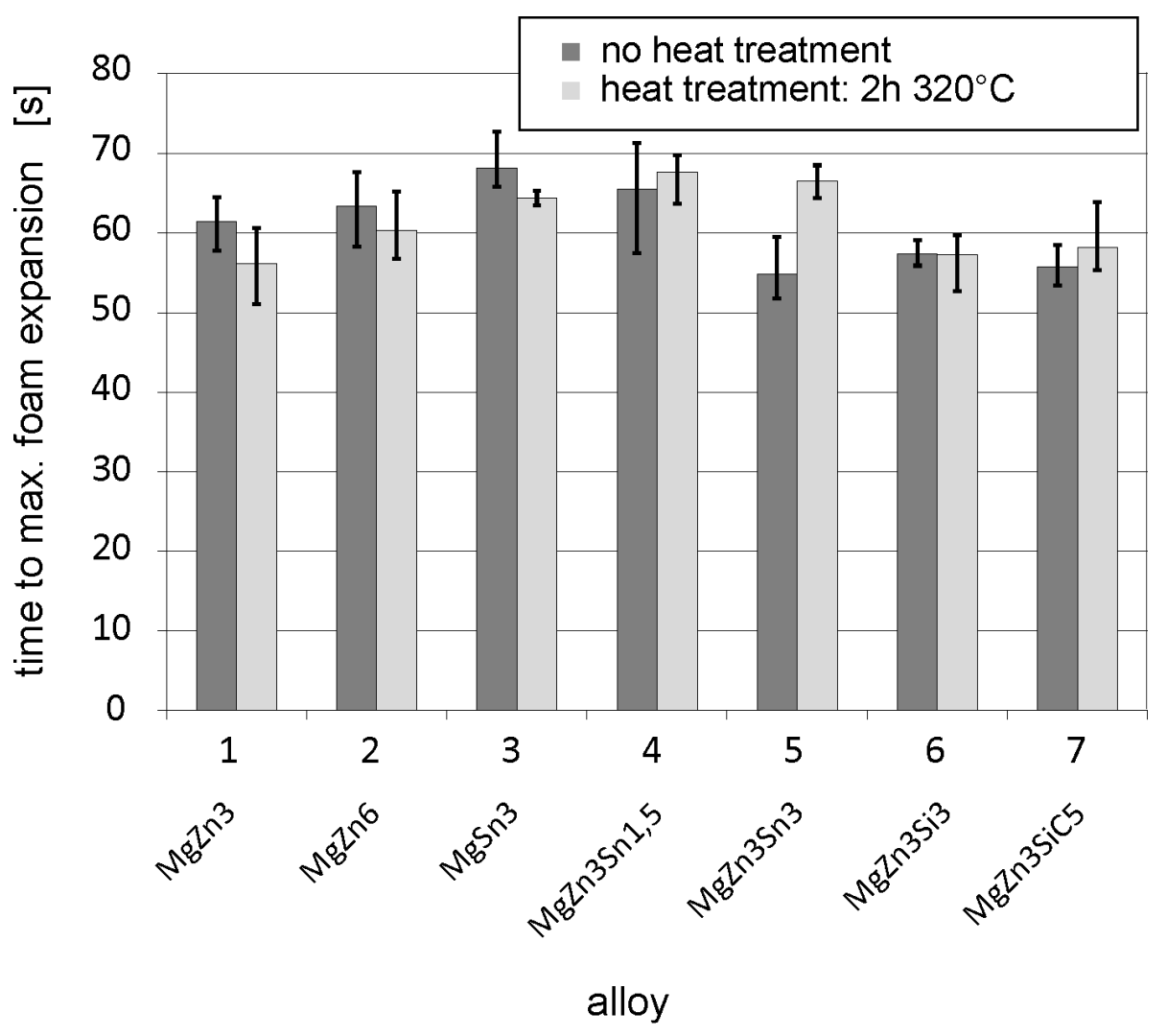

Fig. 10: Foaming times for foamable precursors $(\varnothing 5 \mathrm{~mm}$, length $100 \mathrm{~mm})$ of the alloys from Table 1

However, the foam specimens used to determine the foaming times have a different geometric form to that which is assumed on completion of the foaming process. Fig. 11 depicts three foam products of the reference alloy MgZn3 which have reached their maximum expansion. It can be discerned that the foaming process can begin at different positions in the foamable precursor. In these regions foam collapse, due to the stationary position of the foamable precursor, already occurs even before the product has entirely completed its foaming process. 
Fig. 12 depicts the foam's cross-section with mainly spherically formed pores, which is typical for heat treated MgZn3 alloy.

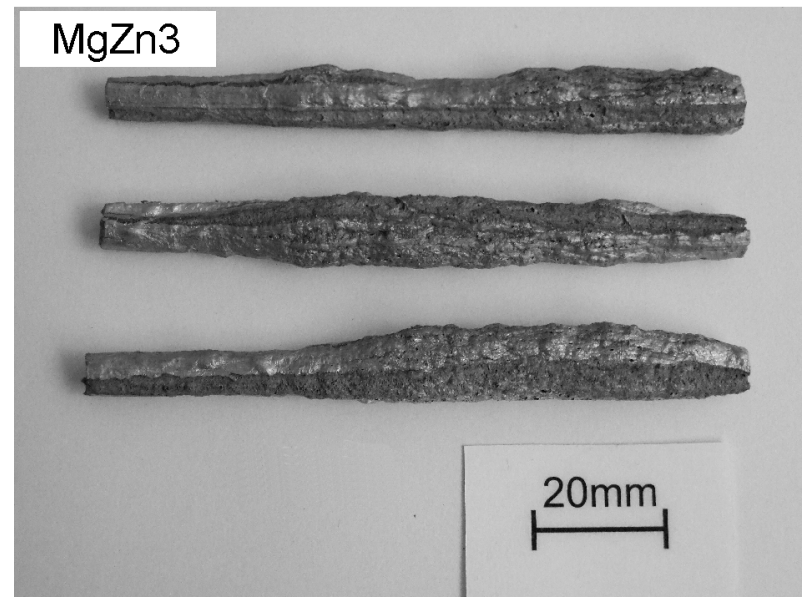

Fig. 11: Foamed specimens for determining the foaming time, alloy $\mathrm{MgZn} 3$, heat treated for $2 \mathrm{~h}$ at $320^{\circ} \mathrm{C}$

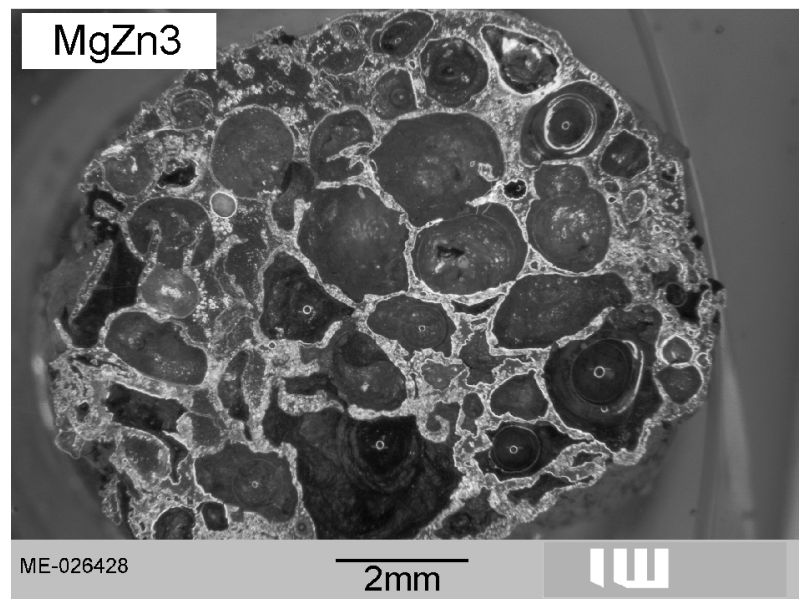

Fig. 12: Cross-section of a foamed specimen for determining the foaming time, alloy $\mathrm{MgZn3}$, heat treated for $2 \mathrm{~h}$ at $320{ }^{\circ} \mathrm{C}$

It was shown in the investigations carried out to determine the foaming time that apart from the MgZn3 alloy, which has already been successfully employed, the alloy containing $3 \mathrm{wt}-\%$ tin exhibited outstanding expansion properties. This is particularly true for the MgSn3 alloy, whose foaming results are depicted in Fig. 13.

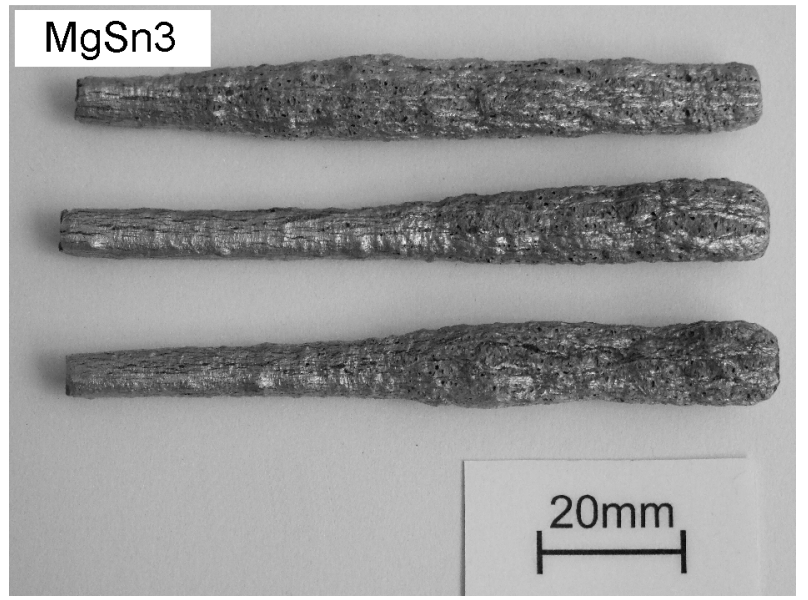

Fig. 13: Foamed specimens for determining the foaming time, alloy $\mathrm{MgSn} 3$, not heattreated

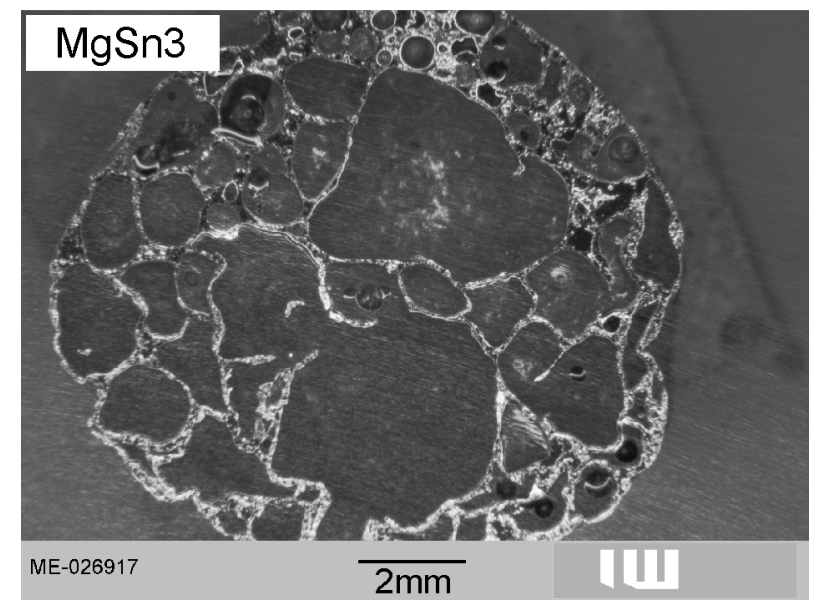

Fig. 14: Cross-section of a foamed specimen for determining the foaming time, alloy MgSn3, not heat-treated

The specimens show large regions of uniform expansion; in part, even over the entire product's length. Contrary to this, if one considers the foam quality obtained for the specimen's cross-section, here strongly pronounced regions of inhomogeneous pore-size distributions are shown, Fig. 14.

To gain further insight into the favourable behaviour of the foam with respect to expansion capacity and foam stability, the MgSn3 foamable precursor were examined using an electron beam microprobe analyser (EBMA). The evaluation of the quantitative line scans can be seen in Fig. 15. 


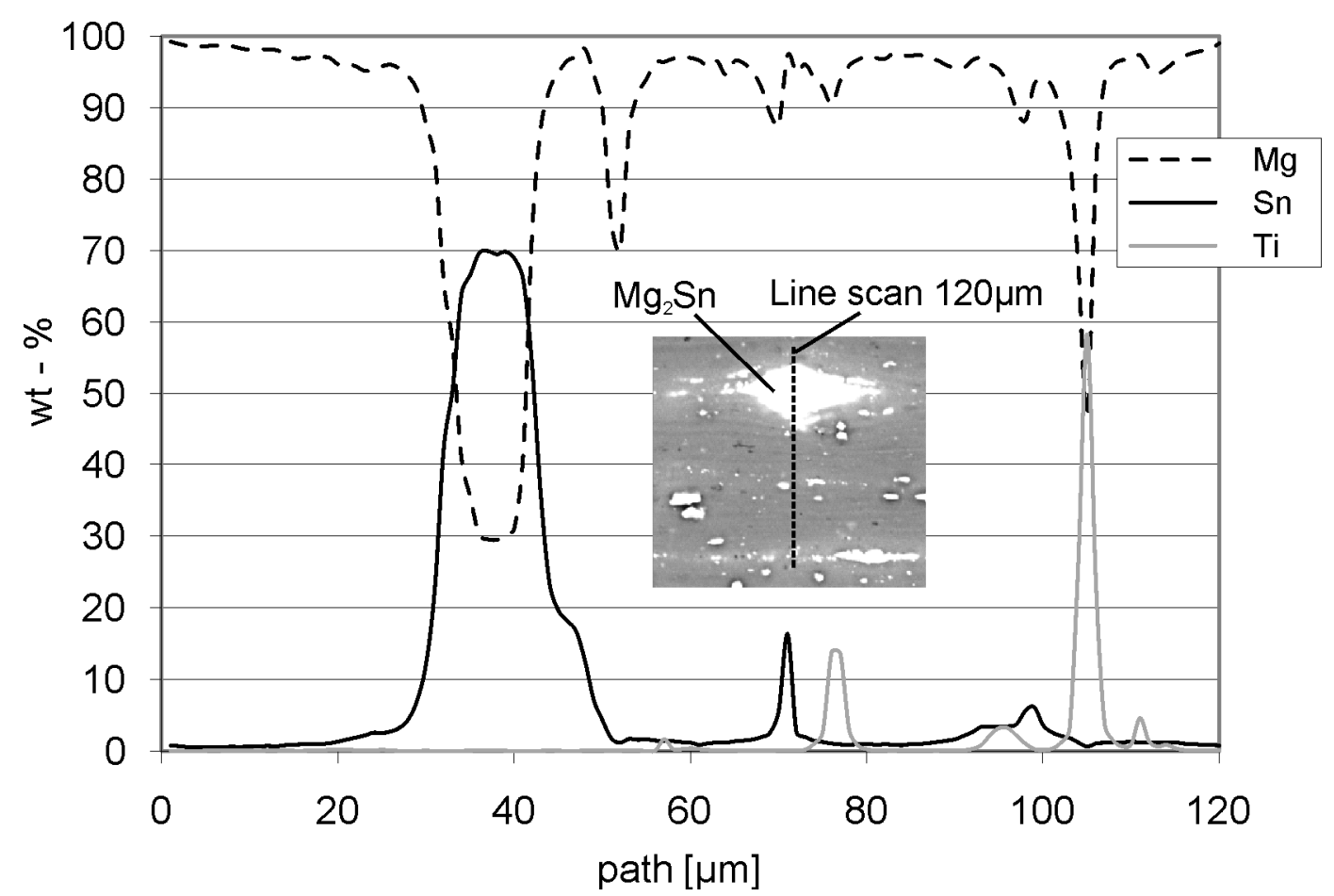

Fig. 15: Line scan (EBMA), $\mathrm{MgSn} 3+1.5 \mathrm{TiH}_{2}$ foamable precursor material, extruded at $300{ }^{\circ} \mathrm{C}$, not heat-treated, longitudinal sample

Different phases can be discerned in the electron reflection pattern shown in Fig. 15. The quantitative evaluation of the line scans and a comparison with the $\mathrm{Mg}$-Sn phase diagrams indicate the formation of the intermetallic phase $\mathrm{Mg}_{2} \mathrm{Sn}$, which computationally consists of $29 \mathrm{wt}-\%$ magnesium and $71 \mathrm{wt}-\%$ tin. Thus subsequent to heat treatment, two phases whose melting points significantly differ exist in the foamed precursor material. It is thus conceivable that a high meltingpoint phase, here the $\mathrm{Mg}_{2} \mathrm{Sn}\left(\mathrm{T}_{\mathrm{L}}=770^{\circ} \mathrm{C}\right)$, can contribute to both increasing the viscosity as well as stabilising the foam during the magnesium matrix's melting process $\left(\mathrm{T}_{\mathrm{L}}=650{ }^{\circ} \mathrm{C}\right)$.

For almost identical expansion properties, the occurrence of significantly differing pore sizes in the foaming state can be effectively countered by either heat treating for $2 \mathrm{~h}$ at $320^{\circ} \mathrm{C}$ (sintering to increase the gas tightness) or by simultaneously adding zinc (primary pore-forming material), see Fig. 16 and Fig. 17. 


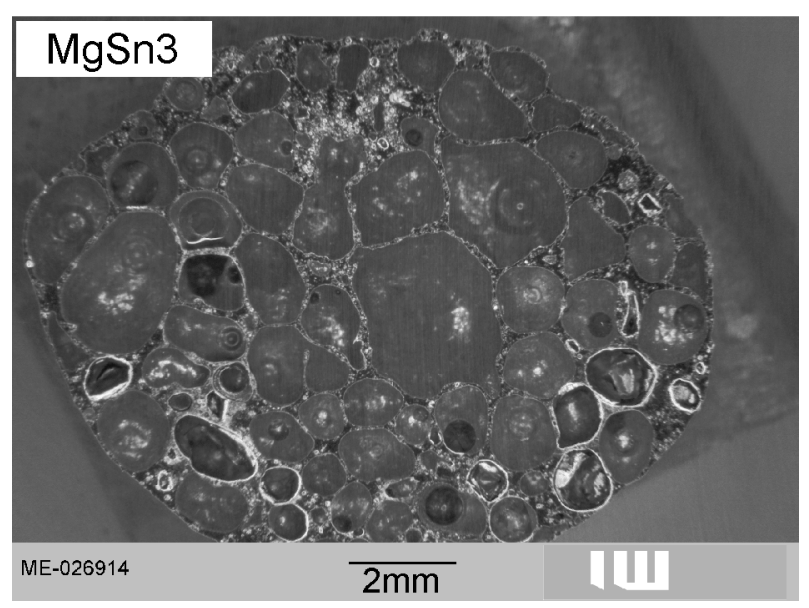

Fig. 16: Cross-section of a foamed specimen for determining the foaming time, alloy $\mathrm{MgSn} 3$, heat treated for $2 \mathrm{~h}$ at $320{ }^{\circ} \mathrm{C}$

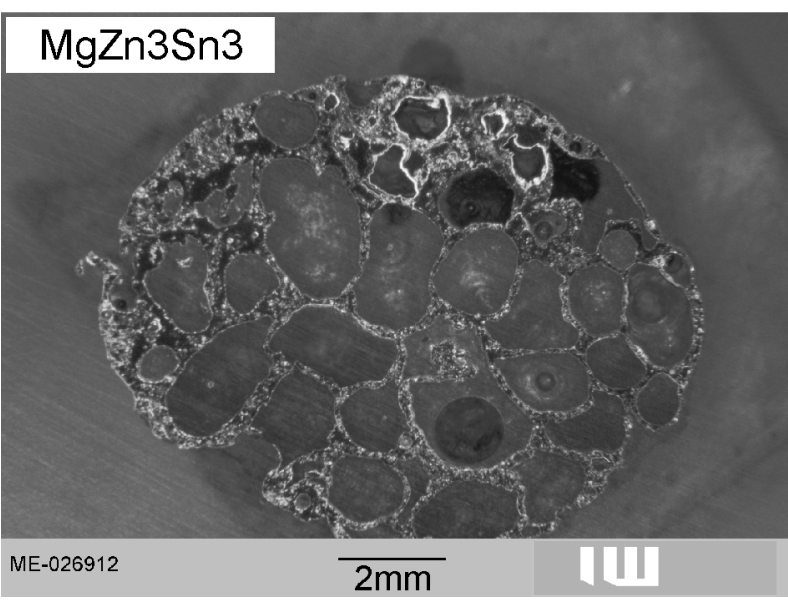

Fig. 17: Cross-section of a foamed specimen for determining the foaming time, alloy $\mathrm{MgZn3Sn3}$, heat treated for $2 \mathrm{~h}$ at $320{ }^{\circ} \mathrm{C}$

In contrast to this, adding $\mathrm{Si}$ and $\mathrm{SiC}$ to increase the viscosity, no significant improvement can be discerned in foam stabilisation and therefore in foam homogeneity with respect to the pore sizes. Fig. 18 and Fig. 19 show examples of torn pore structures in foam produced from the MgZn3SiC5 powder blend. For this reason, only the alloys $\mathrm{MgZn}$ and $\mathrm{MgSn}$ as well as their combination are initially considered in future investigations.

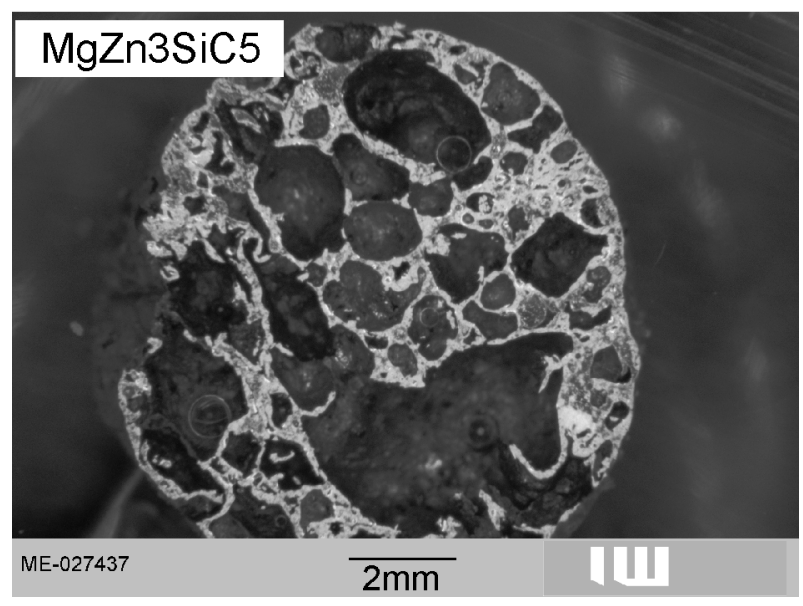

Fig. 18: Cross-section of a foamed specimen for determining the foaming time, alloy MgZn3SiC5, heat treated for $2 \mathrm{~h}$ at $320{ }^{\circ} \mathrm{C}$

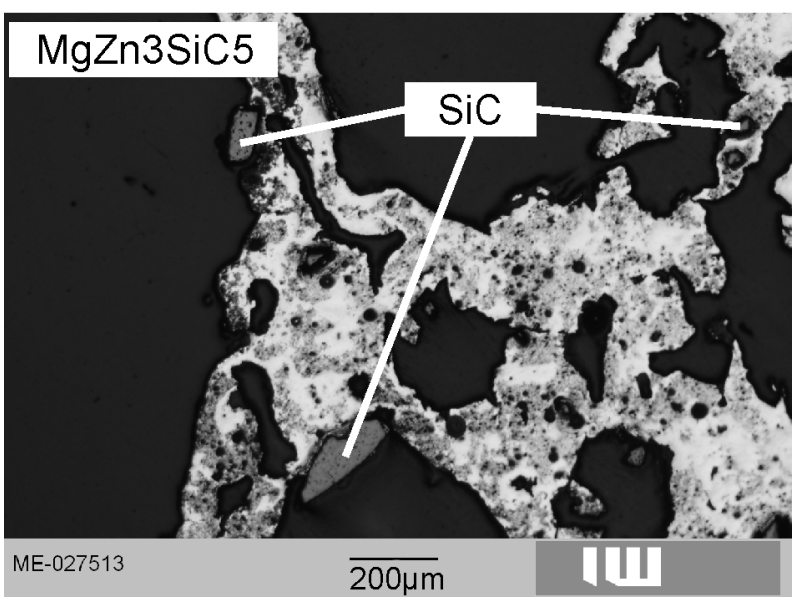

Fig. 19: Cross-sectional micrograph of a $\mathrm{Mg}$ foam's torn cell structure, alloy $\mathrm{MgZn3SiC5}$, heat treated for $2 \mathrm{~h}$ at $320{ }^{\circ} \mathrm{C}$ 
Foaming process. By means of integrating the foaming process of foamable precursor material into a roll forming process, profiles are to be produced which are locally reinforced. Thus, minimising the increase in weight of the entire structure, the absorptive capacity for locally confined operating loads can be significantly improved. For example, in order to fill an $\varnothing 20 \mathrm{~mm}$ tubular profile with $\varnothing 5 \mathrm{~mm}$ foamable precursors, whose manufacture and properties are described above, several of these products are introduced and heated.

Interrupted foaming-tests can be used to illustrate the sequence of events taking place in the continuous foaming process. Fig. 20 depicts one such foam.

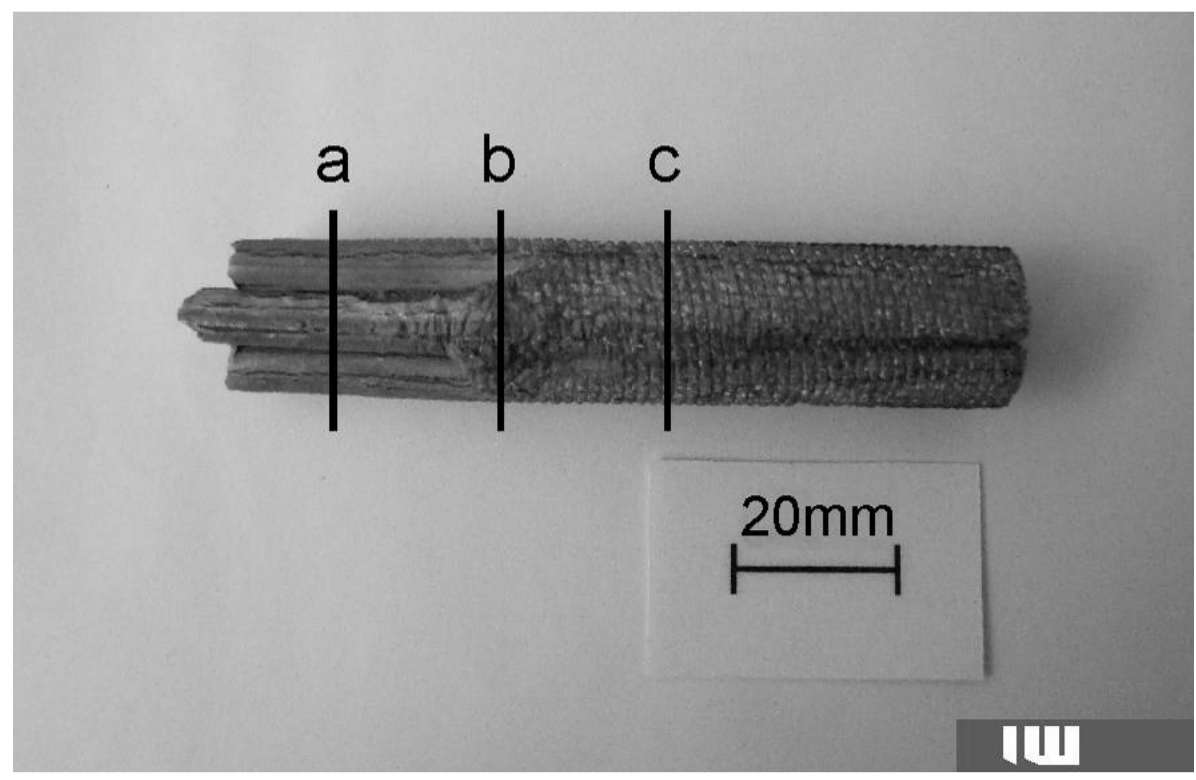

Fig. 20: MgZn3-foam, produced in an interrupted foaming test to illustrate the transition between the foamable precursor material and the completely developed $\mathrm{Mg}$-foam.

The foaming process can be divided into three stages which can be discerned in the foam shown in Fig. 20. In this plan view, one can already differentiate the region of foaming initiation, the transition zone and the completely formed foam. This division is even more apparent on examining the foam's associated cross-section in Fig. 21.

a

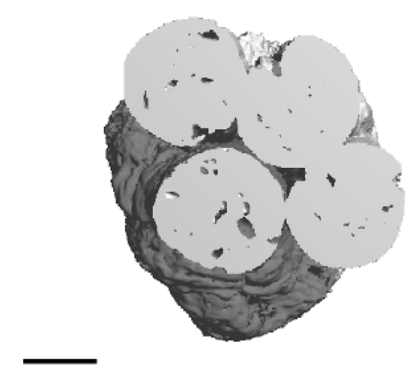

b

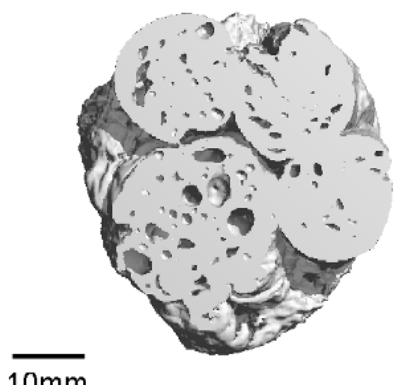

$\overline{10 \mathrm{~mm}}$

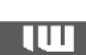

$10 \mathrm{~mm}$

एग1

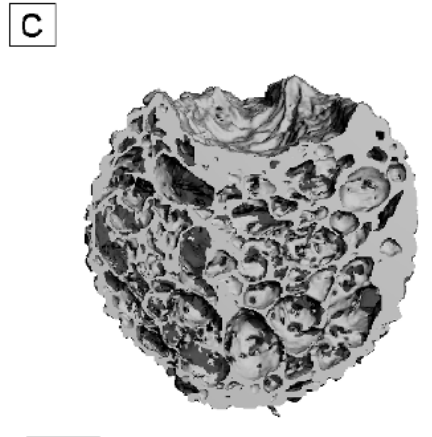

$\overline{10 \mathrm{~mm}}$
DII

Fig. 21: The cross-section's CT images of the different foaming stages during the foaming test from Fig. 20: a) initiation of pore formation in the foamable precursor, b) transition region and c) completely foamed region 
As the foaming process proceeds, individual foamable precursors initially expand by means of pore formation during the thermal decomposition-reaction of the foaming agent (a). On heating further, the boundaries of the foamable precursors are increasingly superseded (b) until finally, a mixture of smelt is obtained and a complete foam structure exists (c).

Influence of shielding gas. In order to guarantee a sufficient shielding-gas atmosphere during the foaming of the $\mathrm{Mg}$ foamable precursor material, the process takes place in a shielding-gas chamber of tubular silica glass which is transparent to infrared radiation. Besides $\mathrm{Ar}+18 \% \mathrm{CO}_{2}$, an $\mathrm{N}+\mathrm{SF}_{6}$ mixture familiar from $\mathrm{Mg}$-casting technology for smelt-shielding was selected as an appropriate shielding-gas.

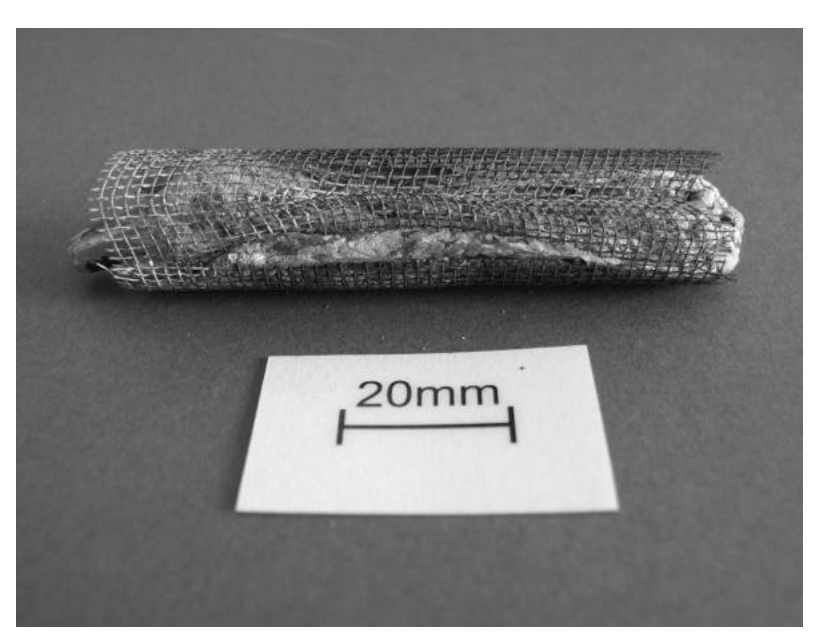

Fig. 22: Collapsed or non-stabilised MgZn3foam with a steel mesh, foamed in $\mathrm{N}+0.6 \% \mathrm{SF}_{6}$ shielding-gas
In order to test the basic suitability of the $\mathrm{N}+\mathrm{SF}_{6}$ mixture as a shielding-gas for manufacturing $\mathrm{Mg}$ foams using the available equipment's technology, foaming tests were carried out subject to flowing gas conditions in the silica glass tube. In contrast to the successful application of $\mathrm{Ar}+18 \% \mathrm{CO}_{2}$ and the concomitant manufacture of homogeneous magnesium foams, no stable Mg-foams could be produced with the shielding-gas $\mathrm{N}+0.6 \% \mathrm{SF}_{6}$ subject to the same flow rate $(41 / \mathrm{min})$, see Fig. 22. In fact, a collapsed and incompletely foamed structure was observed. The $\mathrm{ArCO}_{2}$-gas mixture has the characteristics of a shielding-gas by virtue of the $\mathrm{CO}_{2}$ since a reaction with magnesium occurs which forms a protective coating (this reduces oxidation). Based on this, this type of shielding-gas is employed in the subsequent investigations.

\section{Reinforcement of the magnesium foams}

Due to the low strength of metal foams, investigations were also carried out within the framework of the research work presented here to improve their mechanical properties. One approach is the insertion of reinforcing elements into the foam to support external loads. The investigations were carried out using the $\mathrm{MgZn} 3+1.5 \mathrm{TiH}_{2}$ alloy which had already been the subject of intense research. Reinforcement designs based on steel and titanium were introduced for different stress and strain states. An overview of the elements used can be seen in Table 2.

Table 2: Reinforcing elements used in the tests

\begin{tabular}{|l|l|l|l|}
\hline No. & Reinforcement element & Material No. & Geometry \\
\hline $\mathbf{1}$ & Tensile rod & Steel 1.0570 & $\varnothing 2 \mathrm{~mm}$ \\
\hline $\mathbf{2}$ & Tensile rod & Titanium Gr. 2 & $\varnothing 1.5 \mathrm{~mm}$ \\
\hline $\mathbf{3}$ & Compression spring & Steel 1.4310 & $\varnothing 0.7 \times 11 \mathrm{~mm}$ \\
\hline
\end{tabular}




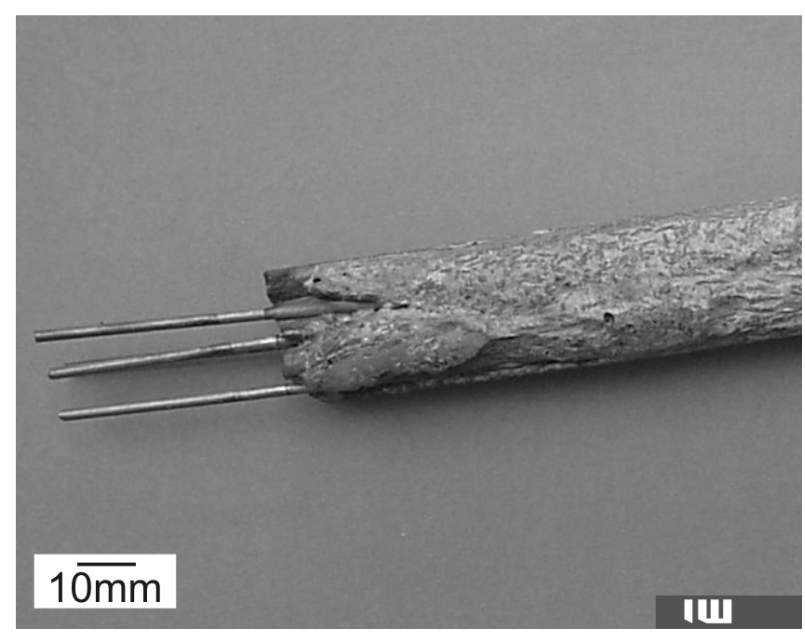

Fig. 23: MgZn3-foam containing tensile rods (1.0570)
Due to the changing heat transfer relationships in the foaming equipment, an individual timetemperature-region was determined for each reinforcing design so that foam parts could be manufactured with fully integrated reinforcements, see Fig. 23. The influence of the reinforcements on the magnesium foam's strength properties was analysed by means of tear-out tests, quasistatic and dynamic compression tests and impact-bending tests as well as by using a specially constructed torsion testing-rig (up to $20 \mathrm{Nm}$ ).

In order to manufacture low-weight-increasing reinforced foams, a combination of reinforcing elements, e.g. tensile rods and springs, were inserted into the foam matrix (Fig. 24). Their locations in the foam can be impressively depicted via analyses using computer tomography, see Fig. 25.
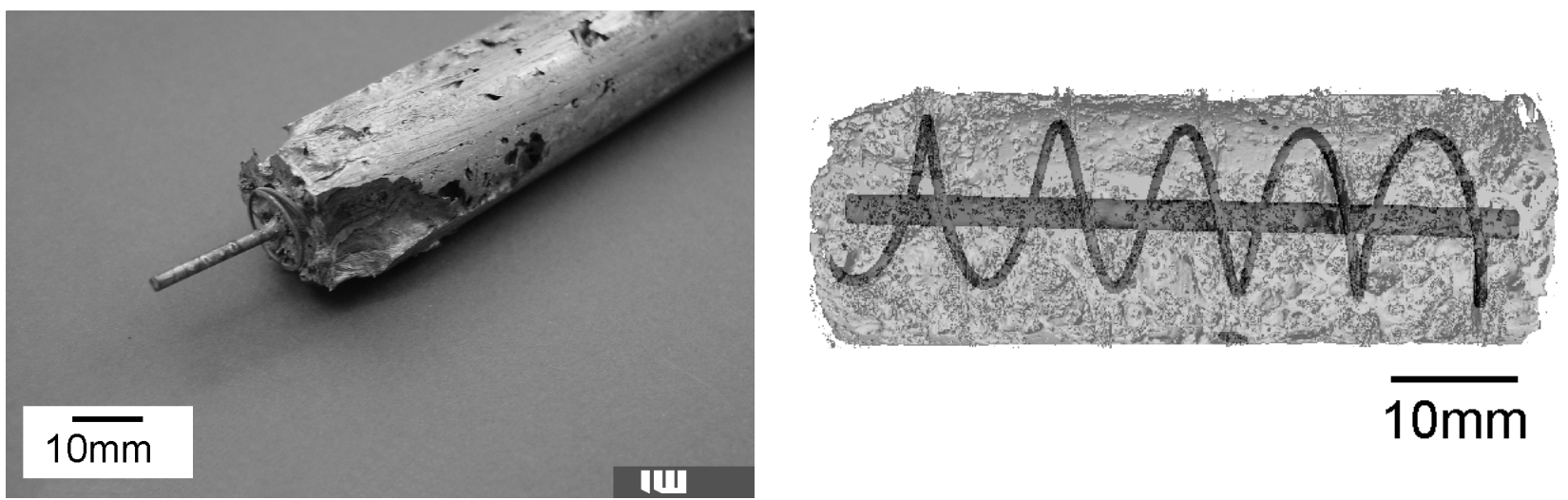

Fig. 24: MgZn3-foam containing reinforcing Fig. 25: CT-image of a reinforced MgZn3-foam elements (tensile rods and springs) containing tensile rods and springs

The influence of the reinforcing elements on the mechanical properties is depicted in Fig. 26: Here, primarily subject to quasi-static compressive loads. In contrast to non-reinforced foams, reinforced foams of comparable density possess a slightly higher initial compressive stress. At this point, the reinforcing elements have still not buckled. However as the loading progresses, the buckling of the reinforcing-struts leads to the preservation of the characteristic compressive stress-strain curve. 

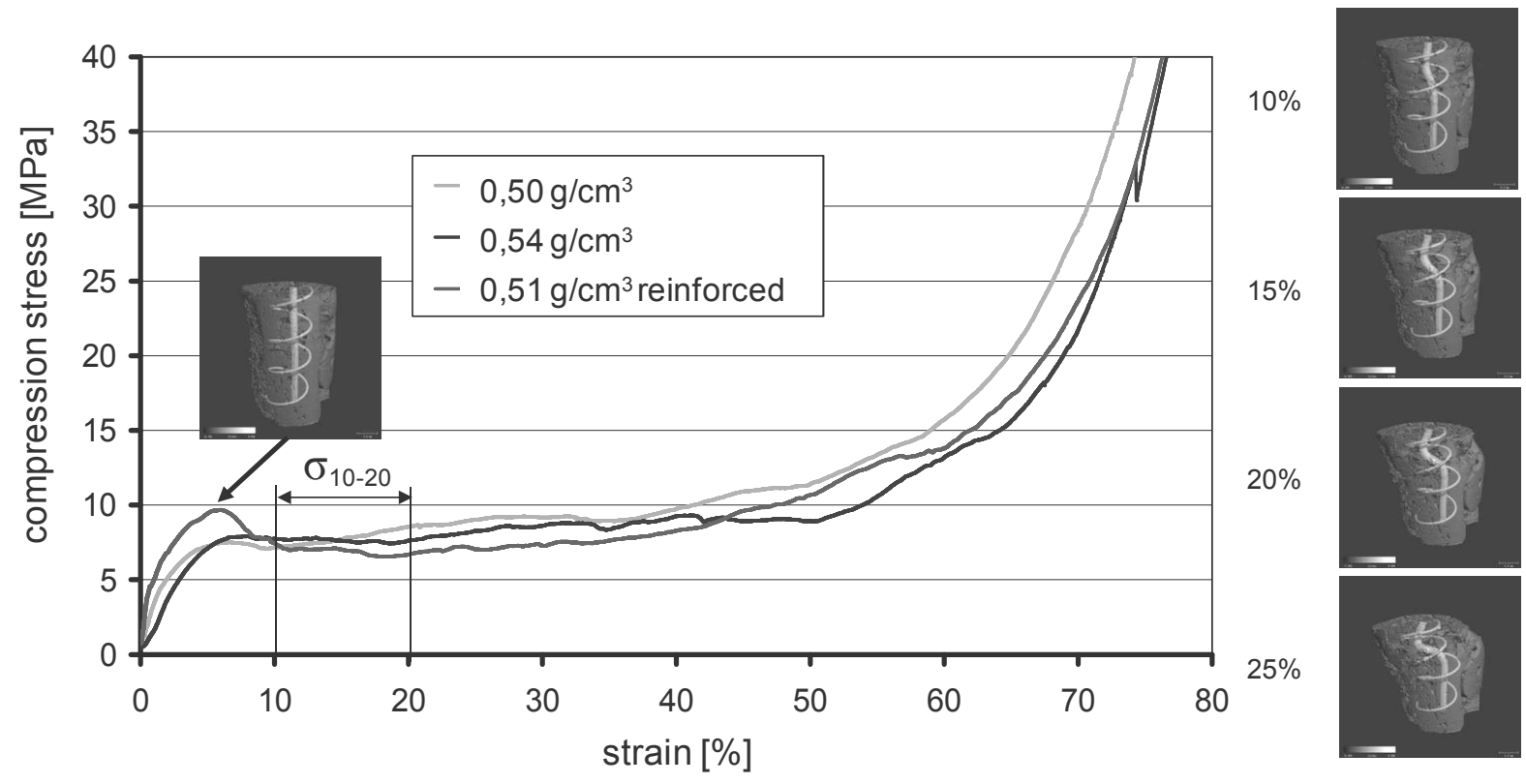

Fig. 26: Compressive stress-strain curves for magnesium foams (reinforced and non-reinforced) of different densities, specimen geometry: $d=23 \mathrm{~mm}, \mathrm{l}=35 \mathrm{~mm}$, cross-head speed 5/1000 s $\mathrm{s}^{-1}$

The integrity of the materials used for the tensile/compressive elements was verified in the tear-out tests, see Fig. 27.

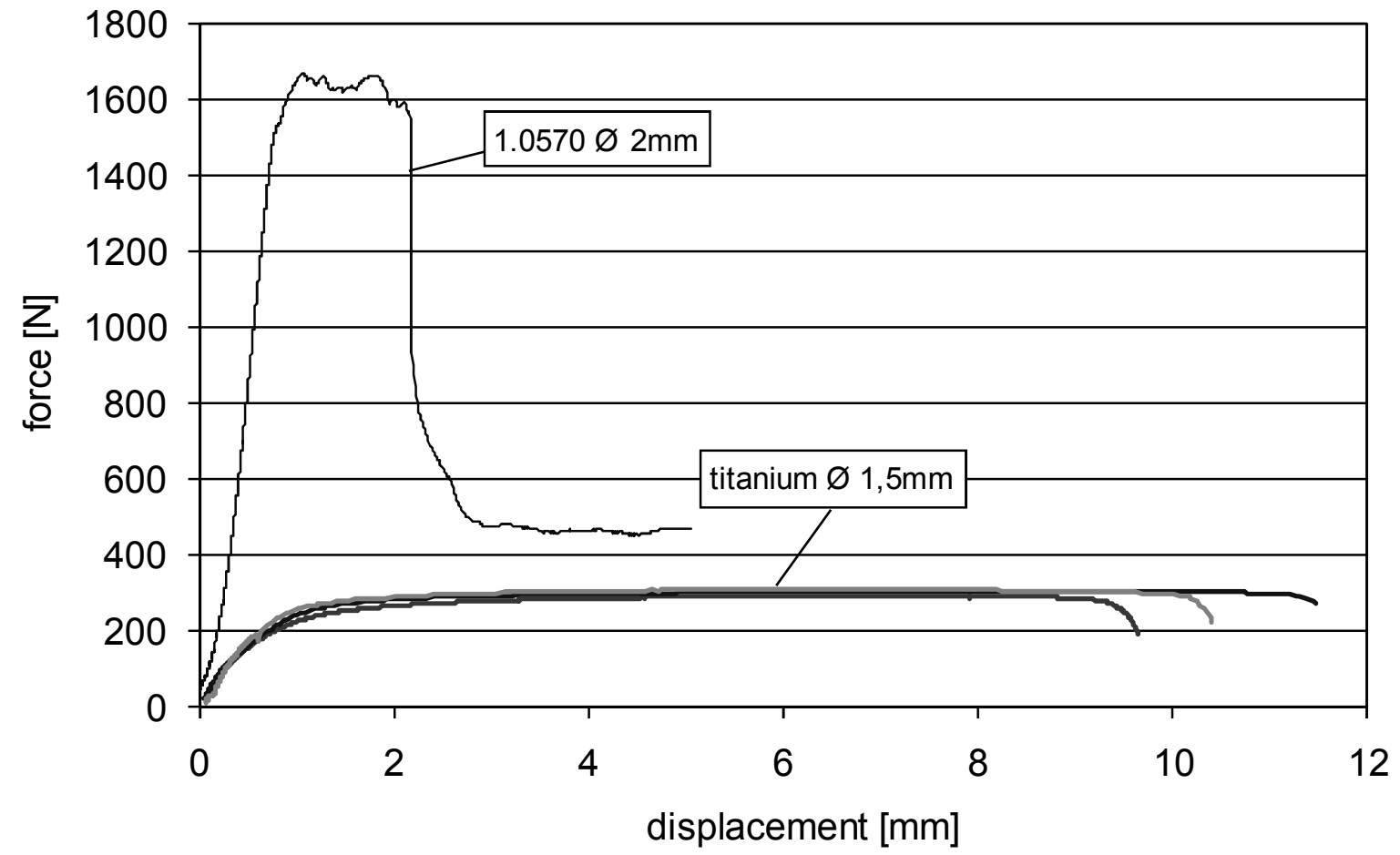

Fig. 27: Force-displacement diagram of the tensile test to determine the tear-out strength of tensile rods inserted into the foam 
It was established that the bonding strength to the foam for the $(\varnothing 1.5 \mathrm{~mm})$ titanium rods exceeded the tensile strength of the titanium so that a tensile-test curve for bulk titanium results for the tearout test. It was shown for the steel tensile-rod (1.0570) that its strength exceeded the bonding to the foam-matrix and detachment took place. A tear-out strength of $1650 \mathrm{~N}$ was measured for steel struts having a diameter of $2 \mathrm{~mm}$ and an $80 \mathrm{~mm}$ embedded depth in the foam. The investigation of the influence of the internal reinforcing elements subject to torsional loading was carried out using a torsion test-rig (up to $30 \mathrm{Nm}$ ) especially constructed for this research project, Fig. 28.

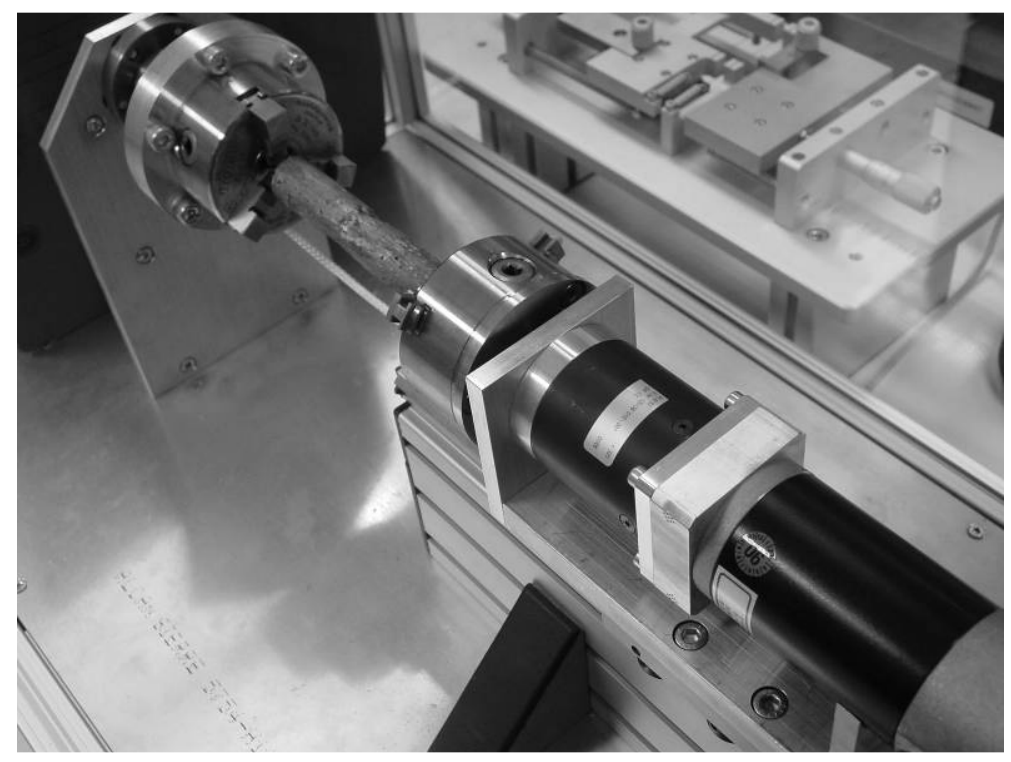

Fig. 28: Torsion test-rig for up to $30 \mathrm{Nm}$

Reinforcing with springs and tensile rods to an average density of $20 \%$ can raise the maximum transmitted torque of Mg-foams by 50\%, Fig. 29.

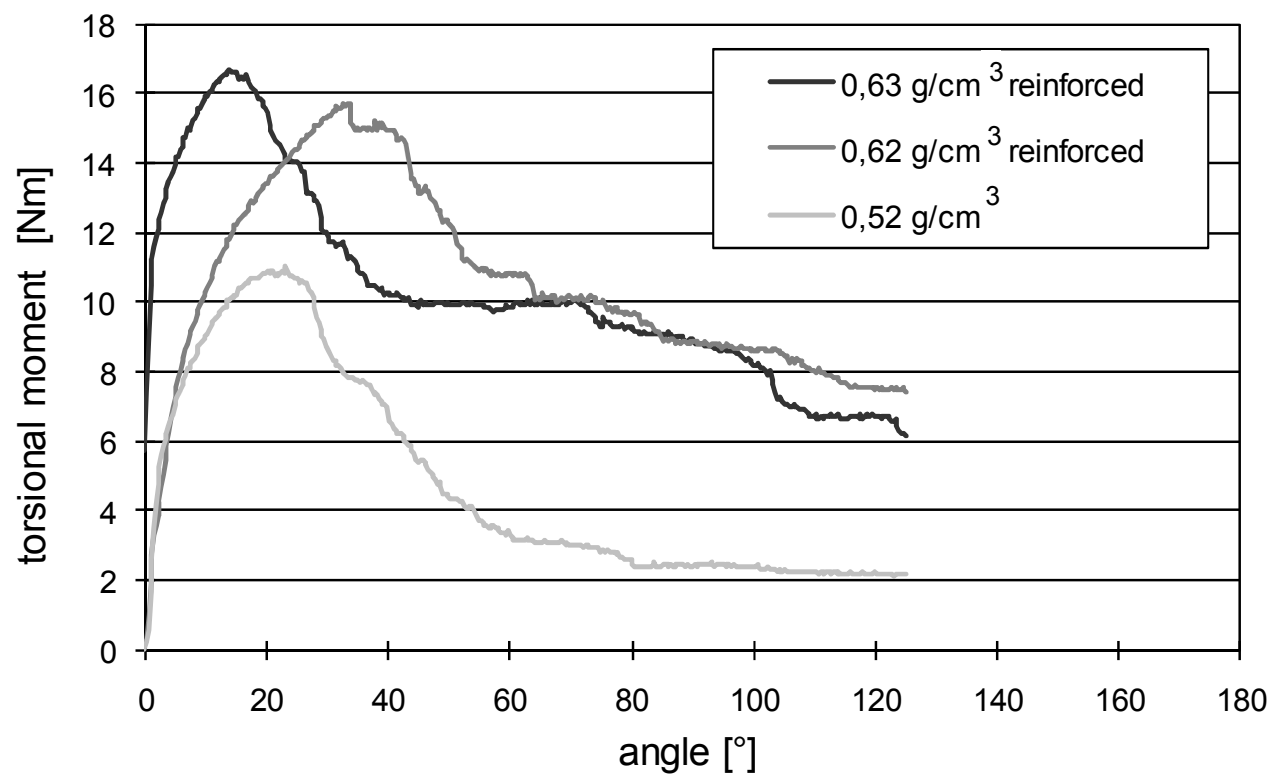

Fig. 29: Comparison of torsional strengths of reinforced and non-reinforced foams (Ø23 x $90 \mathrm{~mm})$ 
Furthermore, with additional reinforcements, incomplete fracture is also exhibited even at a rotation angle of up to $60^{\circ}$. A foam composite results which is sustained via the reinforcing elements, Fig. 30 .
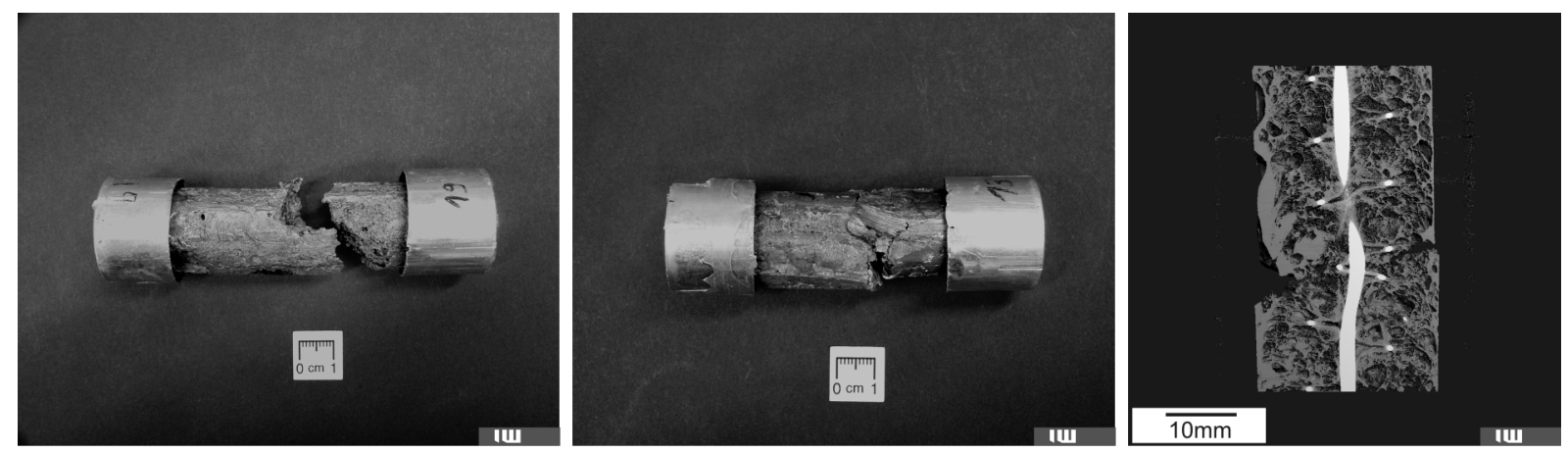

Fig. 30: Torsion specimen, Ø23 mm, length $90 \mathrm{~mm}$ : (left) Mg-foam non-reinforced, (centre) Mgfoam reinforced, (right) computer tomographic image of reinforced MgZn3-foam

If one compares the behaviour of reinforced with non-reinforced foams subject to impact-bending loads, then the influence of the reinforcing elements inserted into the foam becomes even clearer. The determination of required impact energy was carried out using an impact testing machine (nominal energy $150 \mathrm{~J}$ ) made by the company Losenhausen Maschinenbau AG. As expected, nonreinforced foams exhibit very brittle behaviour. This contrasts the Mg-foam that is reinforced with rods and springs, see Fig. 31.

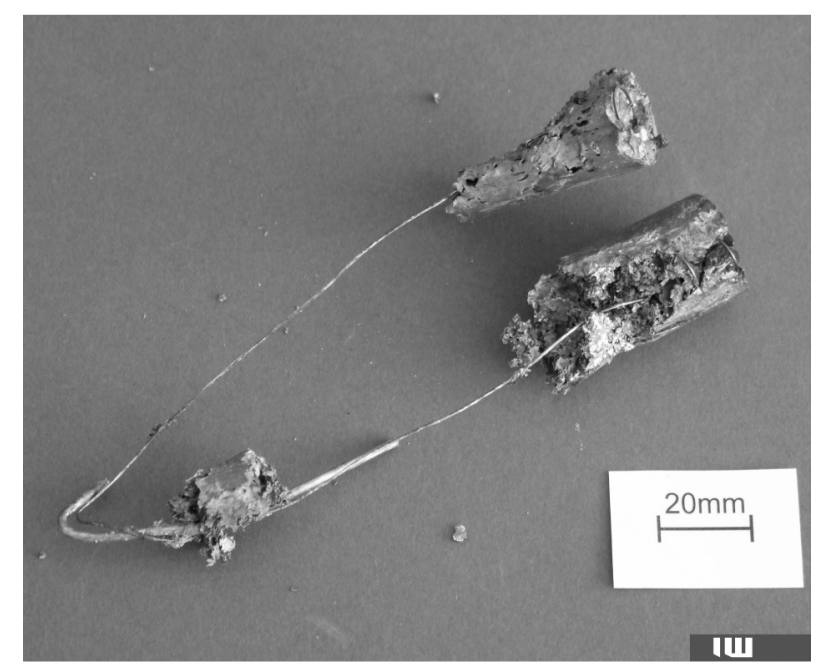

Fig. 31: Torn MgZn3-foam, density $0.55 \mathrm{~g} / \mathrm{cm}^{3}$ containing reinforcing elements, specimen geometry $\varnothing 23 \mathrm{~mm}$, length $90 \mathrm{~mm}$, subjected to an impact-bending test

Here, owing to the required tearing of the reinforcements out of the Mg-foam matrix, a considerable increase of more than a factor of 10 in the required impact energy can be observed for identical densities. As expected, the impact energy rises with the foam density. The measured values are summarised in Table 3.

Table 3: Required impact energy, specimen geometry Ø23 mm, length $90 \mathrm{~mm}$ [18]

\begin{tabular}{|l|l|c|c|}
\hline No. & Test specimen & Overall density $\left[\mathbf{g} / \mathbf{c m}^{\mathbf{3}}\right]$ & Energy $[\mathbf{J}]$ \\
\hline $\mathbf{1}$ & non-reinforced Mg-foam & 0.55 & 9 \\
\hline $\mathbf{2}$ & reinforced Mg-foam & 0.55 & 105 \\
\hline $\mathbf{3}$ & reinforced Mg-foam & 0.59 & 112 \\
\hline $\mathbf{4}$ & reinforced Mg-foam & 0.62 & 131 \\
\hline
\end{tabular}




\section{Local foam-filling of profiles}

Local foam-filling of tubular sections with Mg-foam initially takes place statically at the heating station which was installed for this research project and consists of areal, lineal and spot infrared emitters. These emitters can be employed individually or in combination. The focal distance for focusing the emitters, and thereby the available temperature field for heating the foamable precursor material, was determined with the aid of thermography, see Fig. 32.

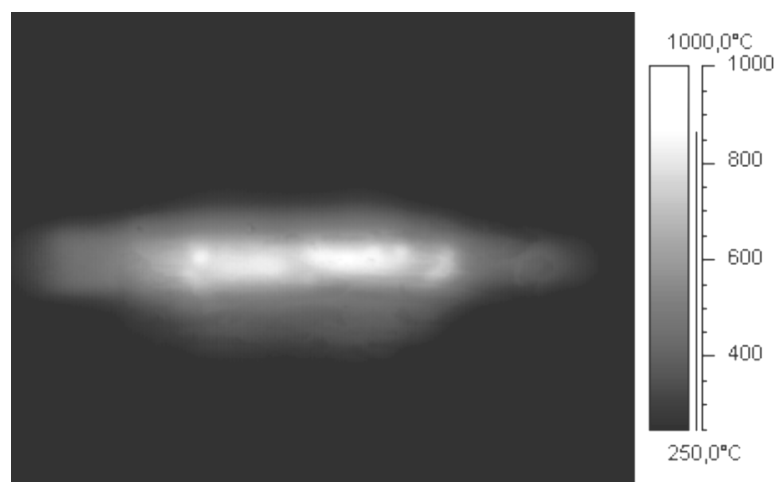

Fig.32: Thermographic image of a surface which is heated by a focused lineal emitter

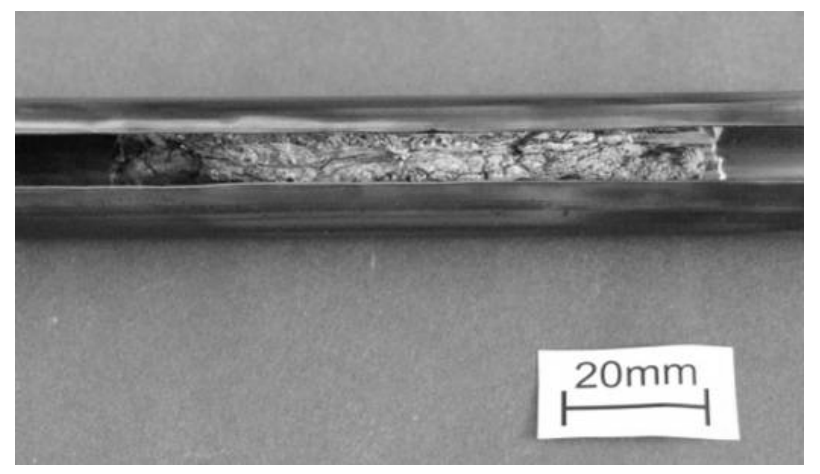

Fig.33: Steel tubing (1.4301) partially foamfilled with $\mathrm{MgZn}_{3}$

By using the tests for partial foam-filling, it was shown that heating on one side through the tube's slit using a $2 \mathrm{~kW}$ lineal, infrared emitter did not lead to complete and homogeneous foam-filling of the tube's cross-section. However, complete heating of the foamable precursors up to the foaming process was realised by simultaneously heating the tube from below using the areal emitter. Fig. 33 depicts one such slit-tube.

The analysis of the foam results for different numbers of contributing foamable precursors yielded that by employing 6 inserted products, the existing slit-tube's cross-section $(\mathrm{d} \sim 23 \mathrm{~mm})$ can be completely filled with foam. The results of the tests using four, five and six foamable precursors can be seen in Fig. 34.
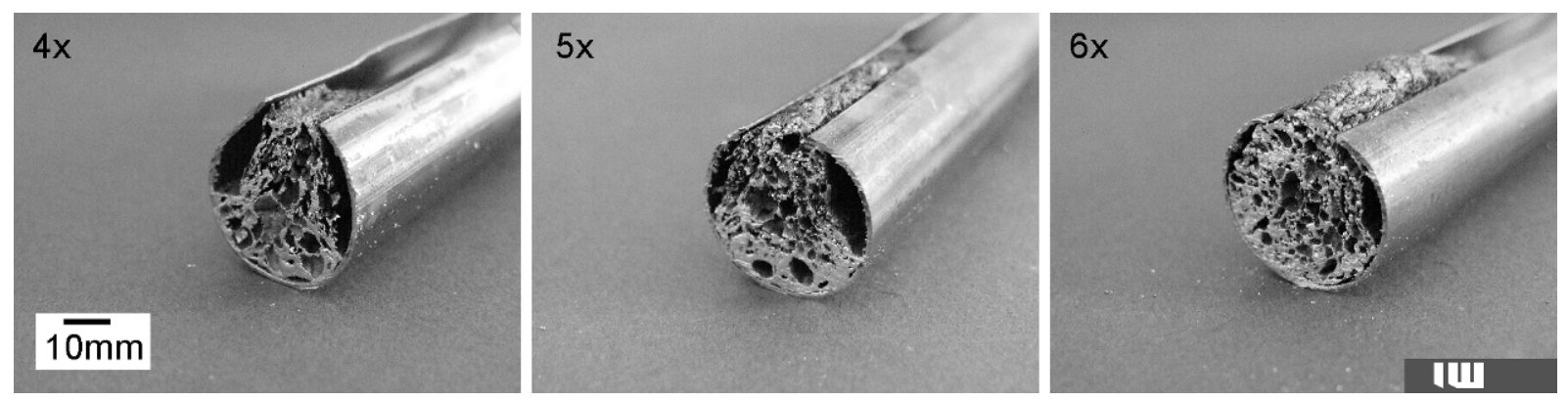

Fig. 32: Partially foam-filled tube using MgZn3, influence of the number of foamable precursors on both the foaming process and the cavity-filling capacity

The over-foaming at the tube's joint region shown in Fig. 34, right, could also be suppressed in subsequent tests by employing a foam barrier. 
Within the framework of this collaborative research centre, roll forming equipment with 16 forming and 2 calibration stations made by the company Nagel Profiliertechnik GmbH was procured and commissioned for the continuous manufacture of profiles, which are locally stiffened using Mgfoam. The heating station consisting of consecutively constructed emitter-units was installed between the "roll forming" and "welding" stations, see Fig. 35.

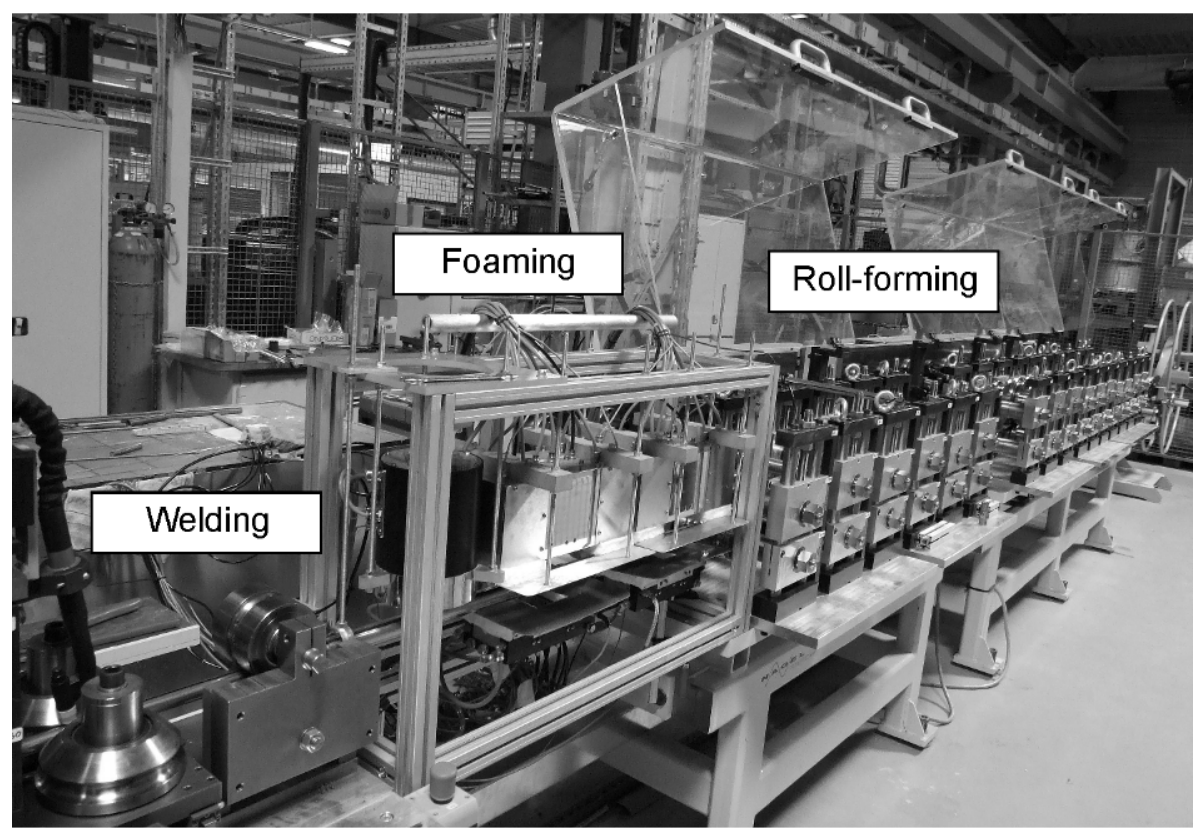

Fig. 33: Roll forming equipment at the Institute of Materials Science (IW), 16 forming and 2 calibration stations

To ensure a shielding-gas atmosphere $\left(\mathrm{Ar}+18 \% \mathrm{CO}_{2}\right)$ during the foaming process, the slit-tube is guided through a silica-glass tube which is transparent to IR-radiation and runs concentric to the array of IR-emitters, see Fig. 36 and Fig. 37.

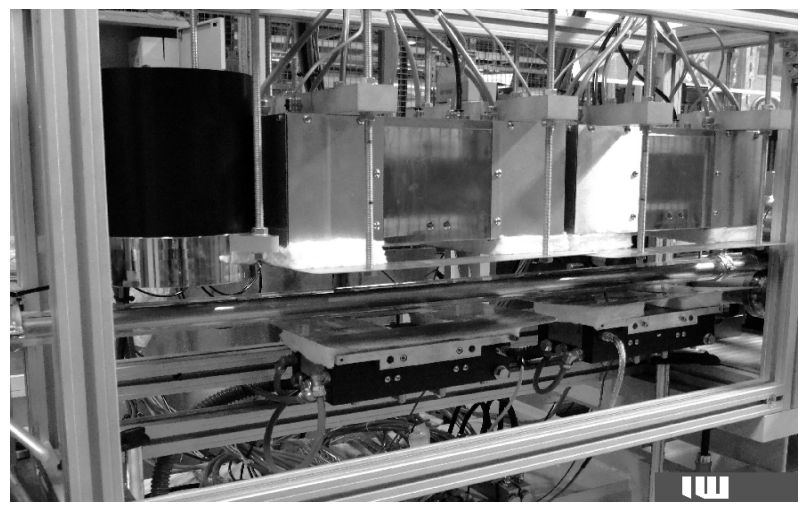

Fig. 34: Heating station showing the spot, lineal and areal IR-emitters from the side

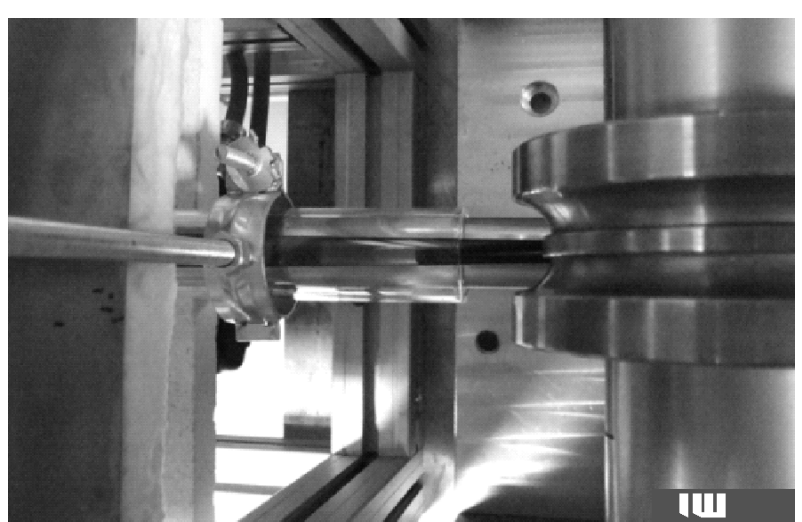

Fig. 35: Plan view of the profiled slit-tube with the shielding-gas chamber of tubular silica glass immediately in front of the IR heating station 


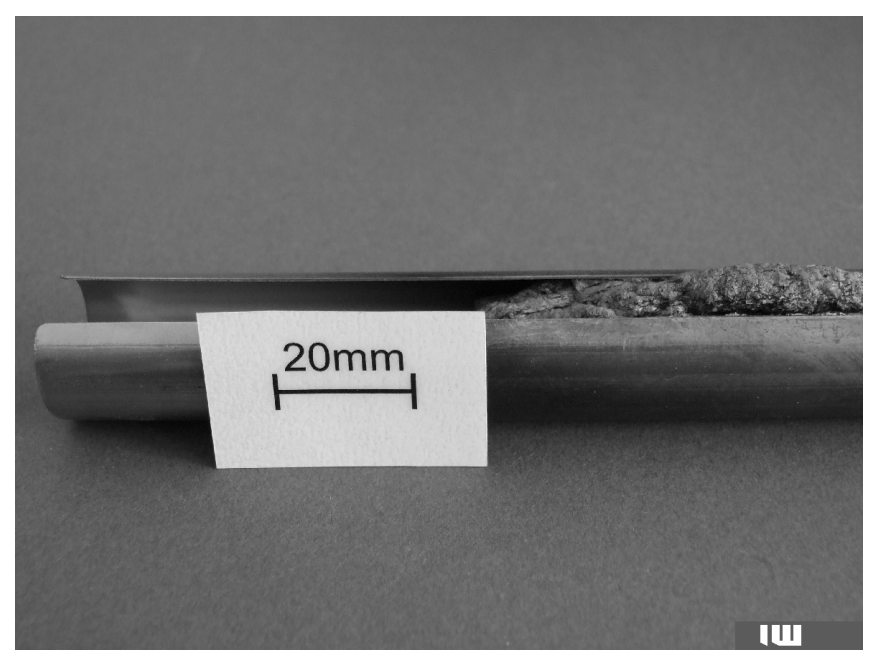

Fig. 36: Over-foaming of a steel tube partially filled with MgZn3-foam

Based on the knowledge gained from static foam-filling of tubular sections, partial foamfilling was realised in the roll forming process. With the aim of obtaining a continuous process chain for profiling with integrated foaming culminating in joining the profile, tests were carried out using various feed rates and distances of the profile to the IR-emitters.

The problem of over-foaming described above, shown again in Fig. 38, was successfully counteracted by inserting a cylindrically formed, stainless steel mesh (Ø0.25 mm wire, $1.4 \times 1.4 \mathrm{~mm}$ mesh size) coaxially into the tube together with the foamable precursor material as a foam barrier, Fig. 39. Due to its grid structure, the barrier is permeable to the IR-radiation and simultaneously restricts the upper foaming region.

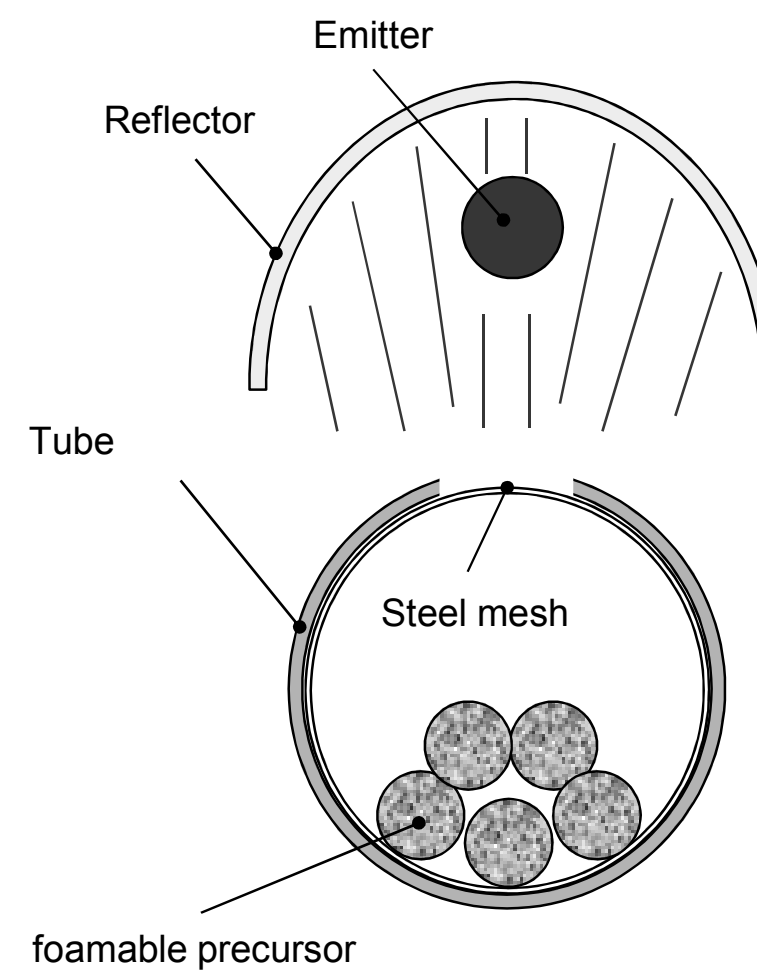

Fig. 37: Method of foam restriction by using barriers during the manufacture of foam-filled profiles

Consequently, by using 5 foamable precursors, it has already been possible to homogeneously foam the cylindrical foam components, which have a length of up to $100 \mathrm{~mm}$, into slit-tubes, see Fig. 40 . In order to obtain as large a contact area as possible between the foam and the tube's wall as well as to simultaneously prevent the foam from escaping, foaming tests were also carried out using semicylindrical mesh-inserts introduced into just the upper half of the tube ( $180^{\circ}$ barriers $)$, see Fig. 41. 


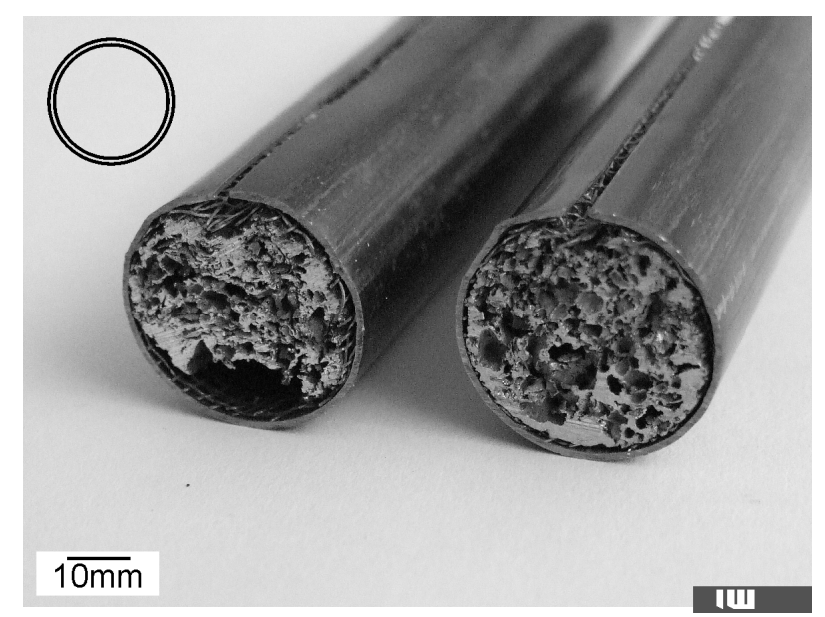

Fig. 38: Locally foam filled tubes (1.4301) with mesh-inserts $\left(360^{\circ}\right)$ as foam barriers

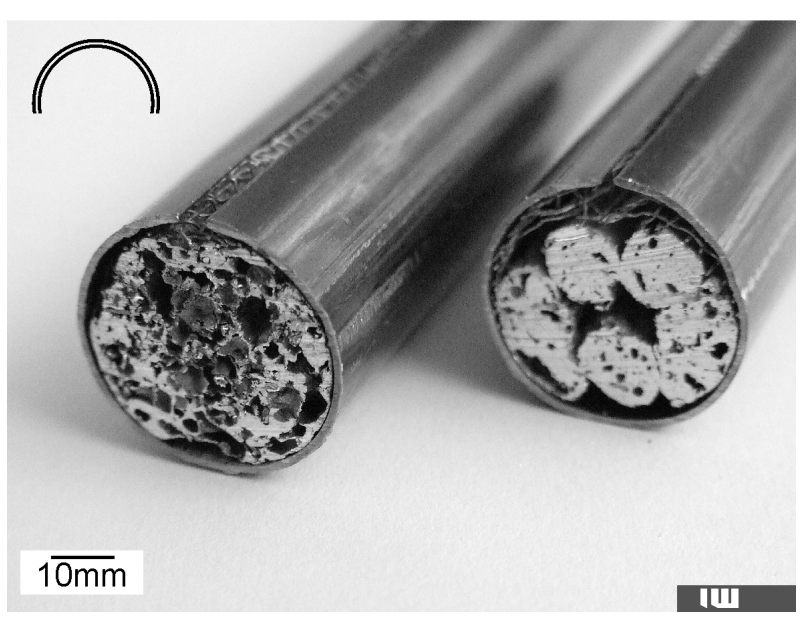

Fig. 39: Locally foam filled tubes (1.4301) with mesh-inserts $\left(180^{\circ}\right)$ as foam barriers, right: incomplete crosssectional filling

By means of this, the slit-tube's feed rate could be increased from $0.11 \mathrm{~m} / \mathrm{min}$. to approx. $0.115 \mathrm{~m} / \mathrm{min}$. A further increase in the feed rate to $0.125 \mathrm{~m} / \mathrm{min}$. leads to the incomplete foaming of the foamable precursors, Fig. 41 right.

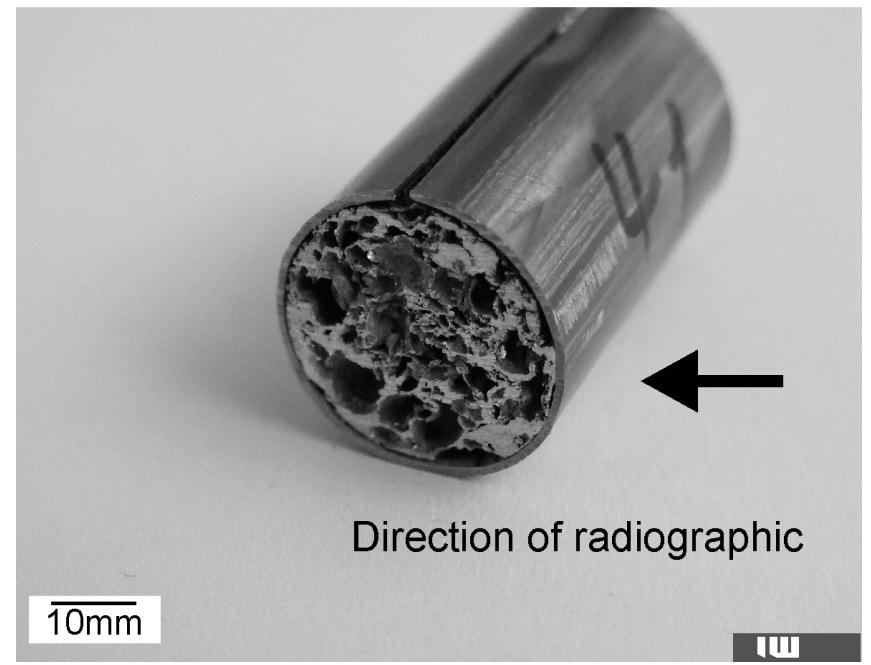

Fig. 40: Foam reinforced tube section $(\varnothing 20 \mathrm{~mm})$ used in for radiographic testing
In order to test both for possible expansion defects in the foam structure as well as for the position of the inserted foam barriers and reinforcing elements, the profiles were radiographed using microfocus x-ray equipment $(160 \mathrm{kV})$ in collaboration with the sub project $\mathrm{C} 4$ (IW) of CRC 675. Fig. 43 shows the summed radiographic image of the foam reinforced tube section from Fig. 42. Both the homogeneous foam distribution in the tube and the position of the foam barrier can be discerned by means of the contrastdistribution across the cross-section. Fig. 44 shows an example of the transition region between a foamed section and the nonreinforced profile-region. 

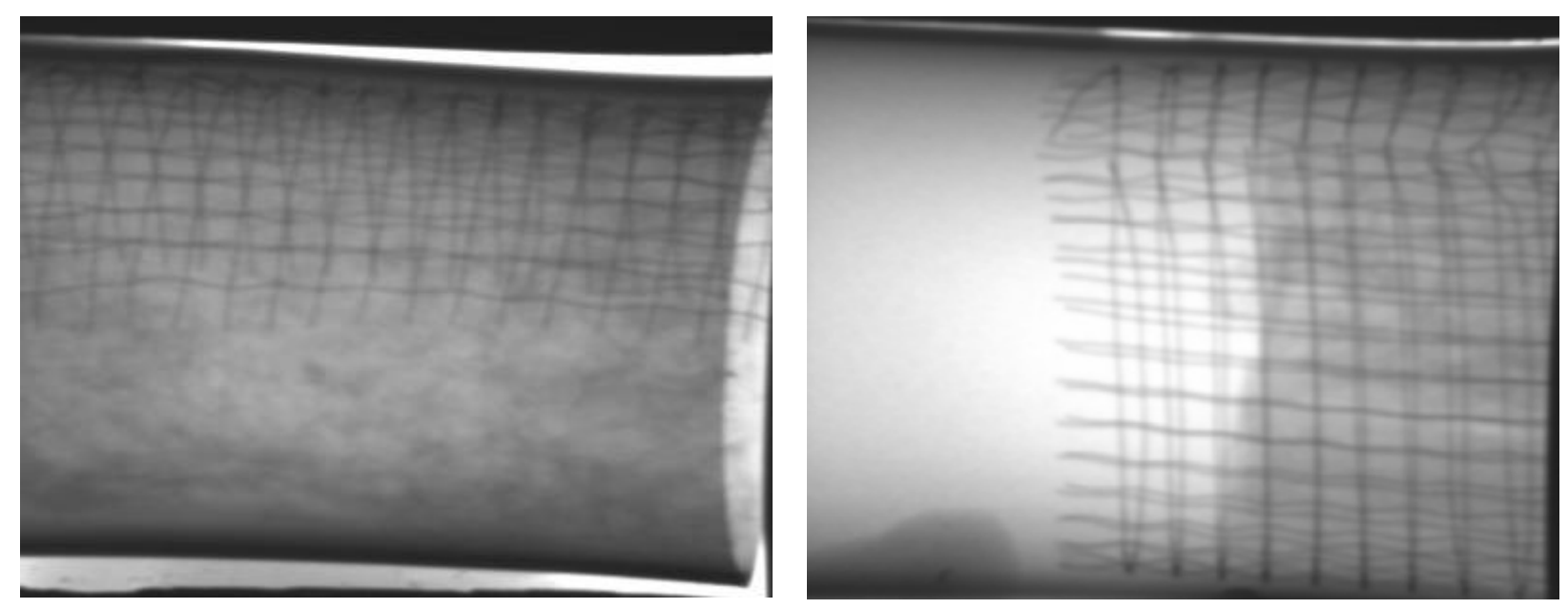

Fig. 41: Radiographic image of the tube's Fig. 42: Radiographic image of a transition section from Fig. 42 region to the foamed profile-region

Based on these investigations for radiographic testing of foamed profiles by means of microfocusradioscopy, an intensification of the collaborative work with the sub project $\mathrm{C} 4$ is planned for the future. Continuous radiographic testing during the foaming process is currently a matter of particular interest for monitoring the foam development in a constantly moving profile. 


\section{Joining locally foamed profiles}

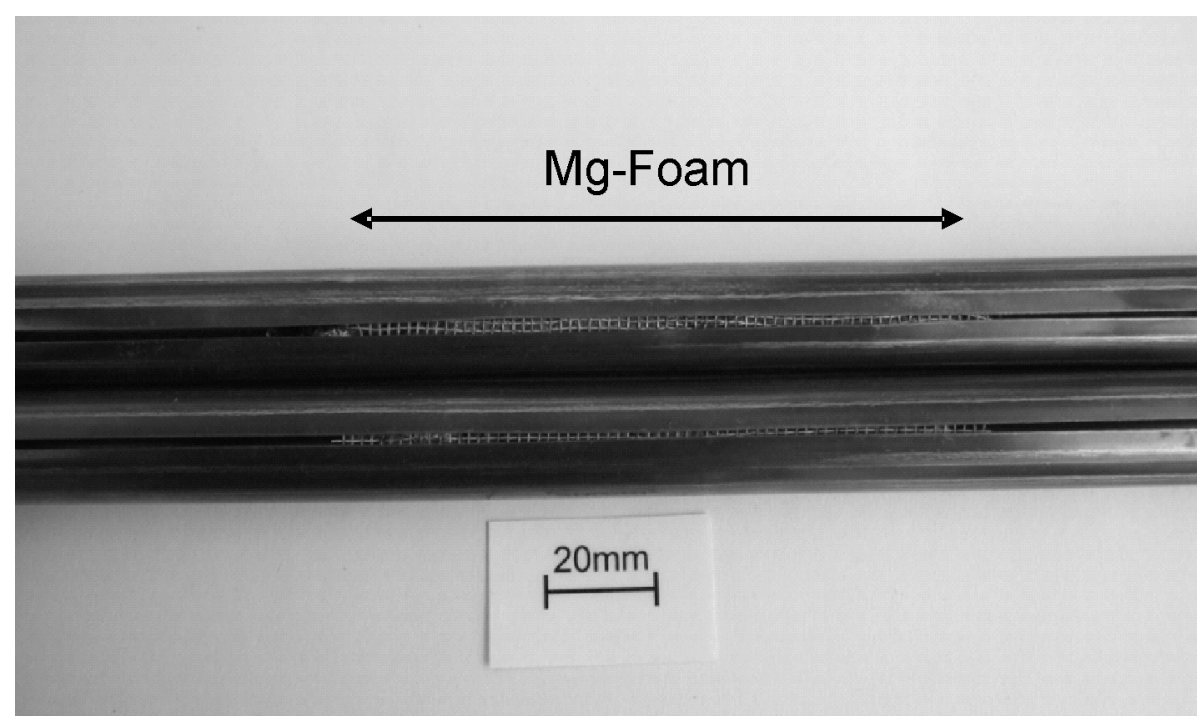

Fig. 43: Locally foamed, profiled 1.4301 stainless-steel slit tubes, non-welded

Joining the profiles, which are partially reinforced with magnesium foam, was coordinated with the project partners in "Joining Technology". Initially, laser beam welding (sub project B1, Laser Zentrum Hannover e.V.) was employed and further tests are planned using high frequency induction welding (sub project B5, ISAF TU Clausthal). It was possible to provide the project partners with finished, profiled split-tube elements reinforced with magnesium foam (Fig. 45).

Sealing sections of split-tube (1.4301), which are locally foam-filled, was successfully implemented in the longitudinal seam-welding tests using a laser ( $Y b: Y A G$ disc laser $3 \mathrm{~kW}$ ) carried out together with the sub project B1 of CRC 675. Based on welding tests carried out on unfilled tubes, a set of parameters was determined for each of the different speeds in the pertinent regions. Fig. 46 depicts a laser welded, foam reinforced tube profile.

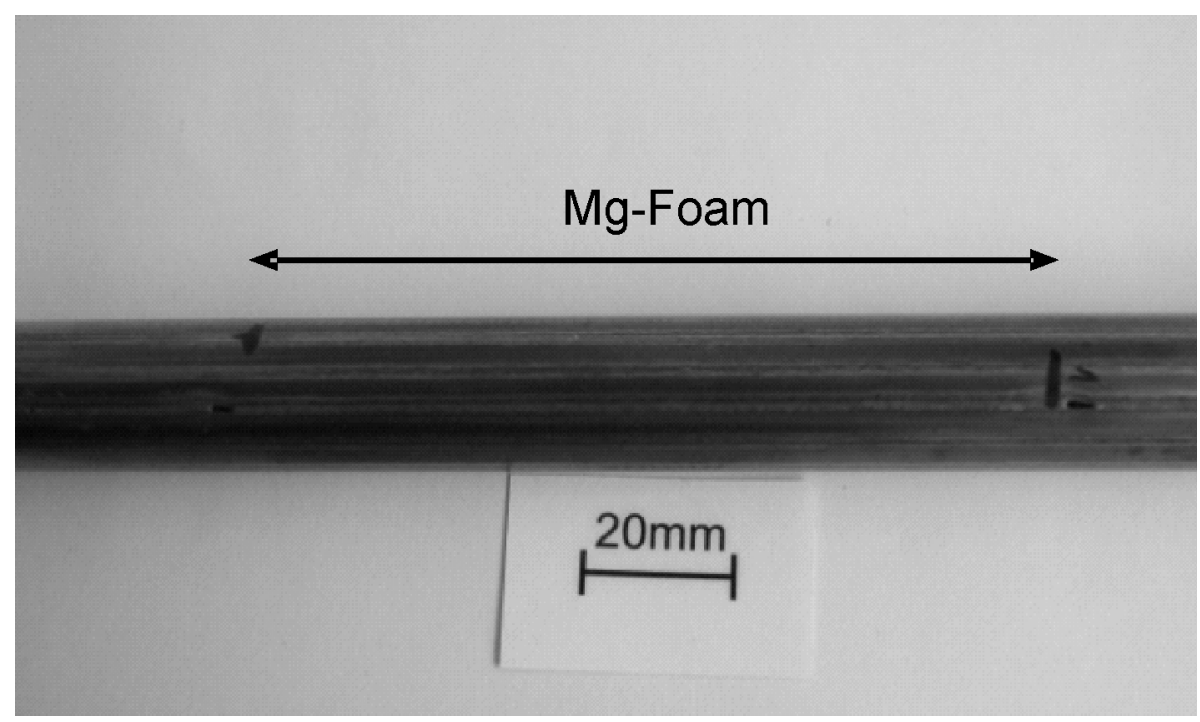

Fig. 44: Locally foam-filled 1.4301 stainless-steel tube $\varnothing 20 \times 0.5 \mathrm{~mm}$, welded using a Yb-YAG disc laser, $1 \mathrm{~m} / \mathrm{min}, 300 \mathrm{~W}$ 
Particular attention was paid to avoid the lack of fusion in the weld seams, particularly at the discontinuous transition region. It was possible to identify two critical regions; on the one hand, the transition between the unfilled tube and the foamed section and, on the other hand, the foam-filled profile sections itself: For example, if the tube can not be sufficiently sealed due to the foam's excessive expansion. Further research is needed with respect to this problem.

Besides this successful application of laser beam welding of the tube sections, longitudinal seam welding of the locally foam-filled profiles was carried out by means of TIG and microplasmawelding, which were integrated into the process in the roll forming equipment. It was possible to verify the successful adaption of TIG and microplasma-welding to the roll forming equipment by means of testing the weld seam on tube sections using a $60^{\circ}$ cone-flaring test. Tube specimens (1.4301) were tested which had been manufactured using a welding speed of $0.1-1 \mathrm{~m} / \mathrm{min}$. All specimens endured an expansion of the diameter of more than $20 \%$ without cracking. In Fig. 47 , an example of a flared tube section (Ø20 mm, $30 \mathrm{~mm}$ long) can be seen following the test.

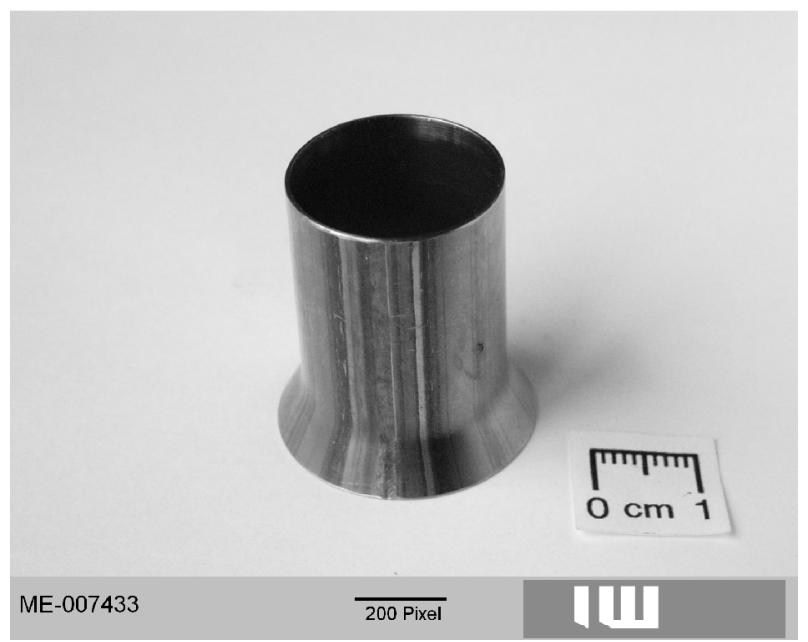

Fig. 45: Section of a stainless-steel tube (1.4301), tested in a cone-flaring test $\left(60^{\circ}\right)$

In subsequent joining tests, completely welded, locally foam-filled composite profiles were successfully manufactured, see Fig. 48.

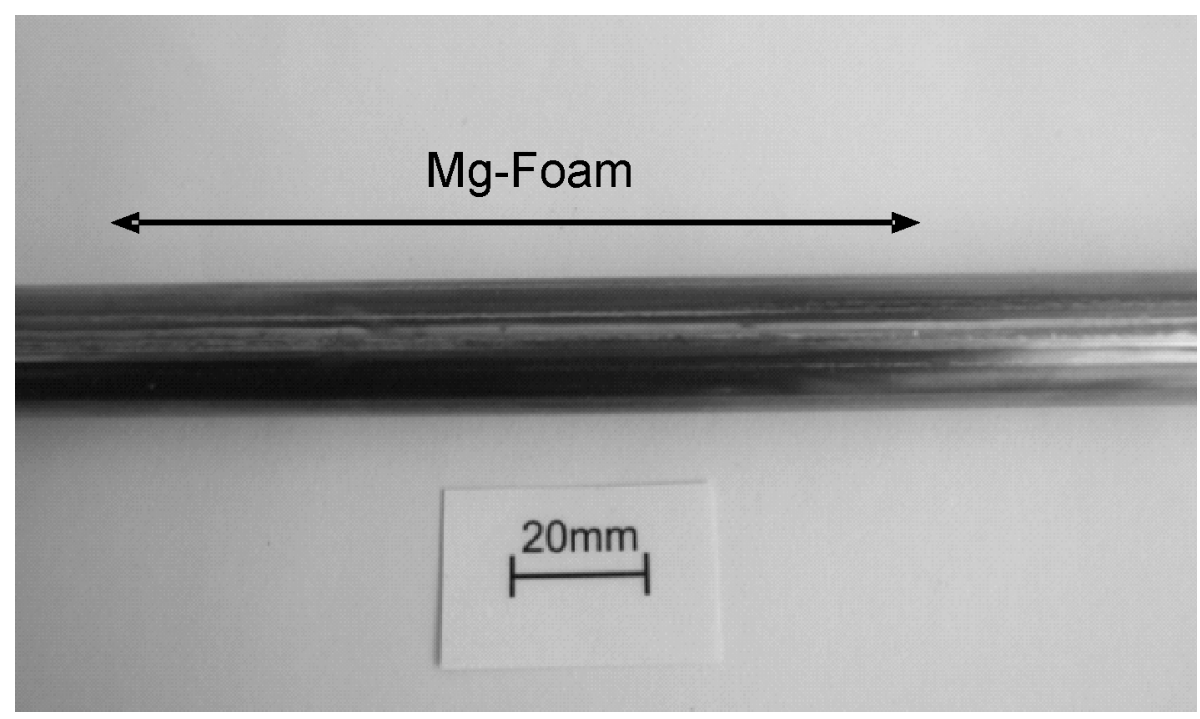

Fig. 46: Locally foam-filled 1.4301 stainless-steel tubes $\varnothing 20 \times 0.5 \mathrm{~mm}$, welded using microplasma $15.5 \mathrm{~A}, 0.5 \mathrm{~m} / \mathrm{min}$ 


\section{Testing locally foam-filled profiles}

Non-destructive testing. With the aid of a Resonant Frequency Damping Analyser (RFDA, Fig. 49) which was procured within the framework of CRC 675, it was possible to conduct a nondestructive material and component test with respect to their vibrational behaviours. To determine the Young's and shear moduli as well as the resonance frequencies and damping, specimens are excited by means of a mechanical impulse. The vibrations of the test piece are detected by an acoustic sensor, analysed and graphically visualised using the RFDA's plotter.

A comparison of the damping of non-welded slit-tubes with and without local foam reinforcements is depict in Fig. 50. Even here, a clear rise in damping can be discerned.

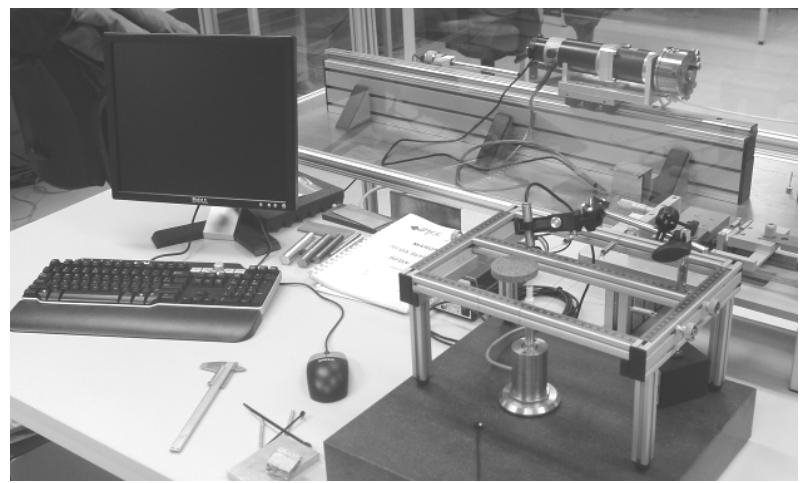

Fig. 47: RFDA MF23 made by the company Integrated Material Control Engineering (IMCE N.V.)

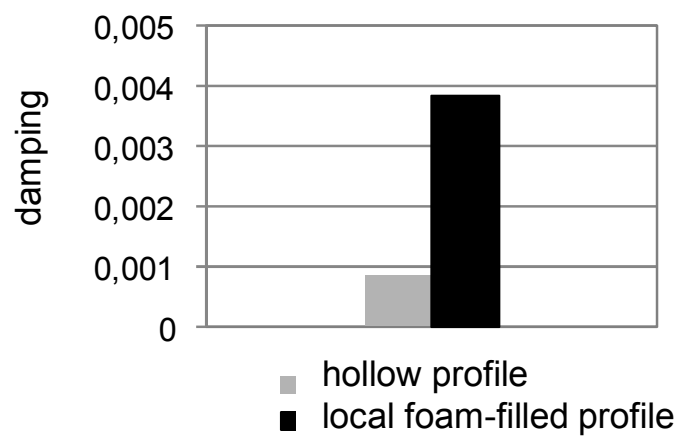

Fig. 48: Comparison of damping of a locally foam-filled and non-filled tube (each $250 \mathrm{~mm}$ long)

Destructive testing. The steel tubes which are locally reinforced with $\mathrm{Mg}$-foam and longitudinally seam-welded were tested in 3-point bending and the results compared with those from nonreinforced tubes. Fig. 51 shows a reinforced tube following the bend test. The extension and compression of the foam insert can be clearly discerned on the foam-insert's tensile and compressive sides, respectively.

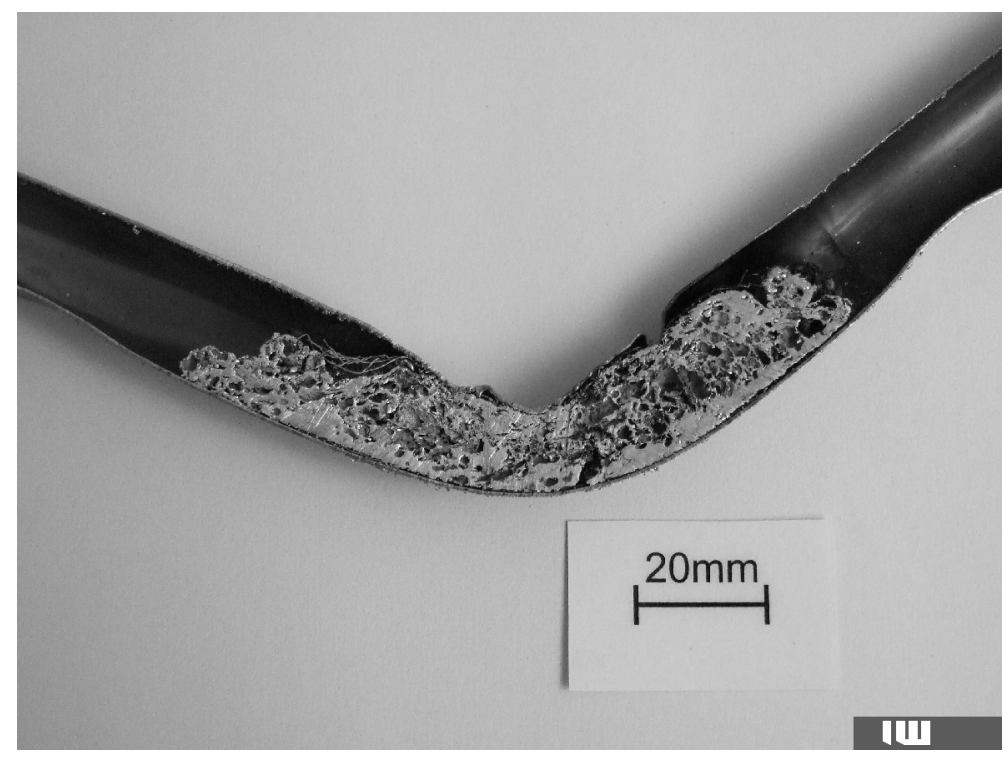

Fig. 49: Longitudinal section of a 1.4301 stainless-steel tube (Ø20 mm, $250 \mathrm{~mm}$ long), tested in 3point bending, span width $160 \mathrm{~mm}$ 
Fig. 52 shows that the bending strength $(816 \mathrm{MPa})$ which, in this case, was attained with a $75 \mathrm{~mm}$ long Mg-foam reinforcement is higher than that for a non-filled tube (292 MPa) by a factor of $\sim 2.8$. The increase in weight of $14 \mathrm{~g}$, due to the foam, corresponds to merely $23 \%$ for the tested tube length of $250 \mathrm{~mm}$. This increase in bending strength demonstrates once again the enormous potential of locally reinforcing hollow profiles with foam.

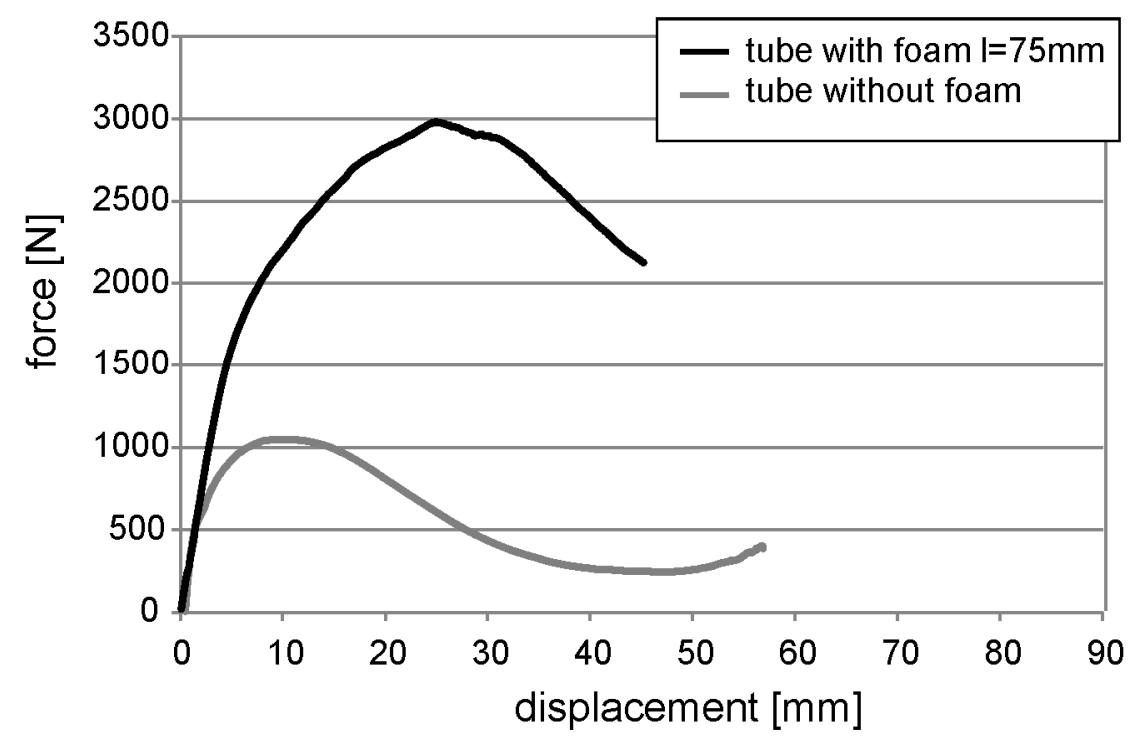

Fig. 50: Force-displacement curve for both locally foam-filled and non-reinforced 1.4301 annular tubing $(\varnothing 20 \times 0.5 \mathrm{~mm})$ test in 3-point bending (span width $160 \mathrm{~mm}$ ) 


\section{Prospects - Manufacturing of magnesium profiles}

Investigations into manufacturing ultra-light, homogenous magnesium-foam composite profiles will be a future focus of the research work in this sub project. With the aid of the knowledge hitherto gained in this project, it was possible in an initial feasibility study to realise a novel method of developing ultra-light construction elements based on magnesium [19].

For this purpose, $61.1 \times 0.5 \mathrm{~mm} \mathrm{AZ31} \mathrm{flat} \mathrm{strip} \mathrm{Fig.} \mathrm{54)} \mathrm{was} \mathrm{manufactured} \mathrm{using} \mathrm{the} \mathrm{Institute's}$ own 10 MN SMS Meer extruder.

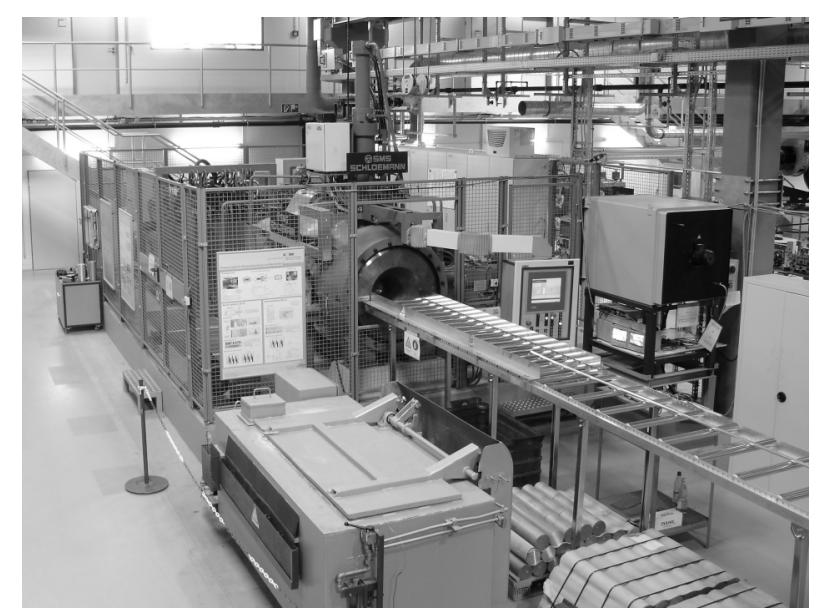

Fig. 51: Institute of Materials Science's (IW) $10 \mathrm{MN}$ extruder (made by the company SMS Meer)

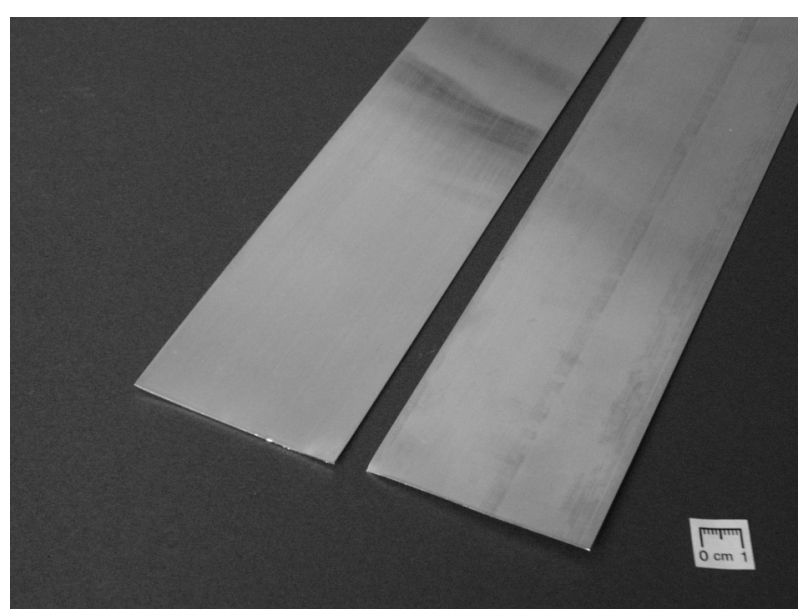

Fig. 52: Extruded Mg flat profiles (AZ31), $61.1 \times 0.5 \mathrm{~mm}$

These dimensions are suitable for further processing directly on the roll forming equipment to produce annular tubes $\varnothing 20 \times 0.5 \mathrm{~mm}$. The start material was mechanically characterised in collaboration with the Institute of Metal Forming and Metal-Forming Machines. The results of a cupping-test according to Erichsen are shown in Fig. 55.

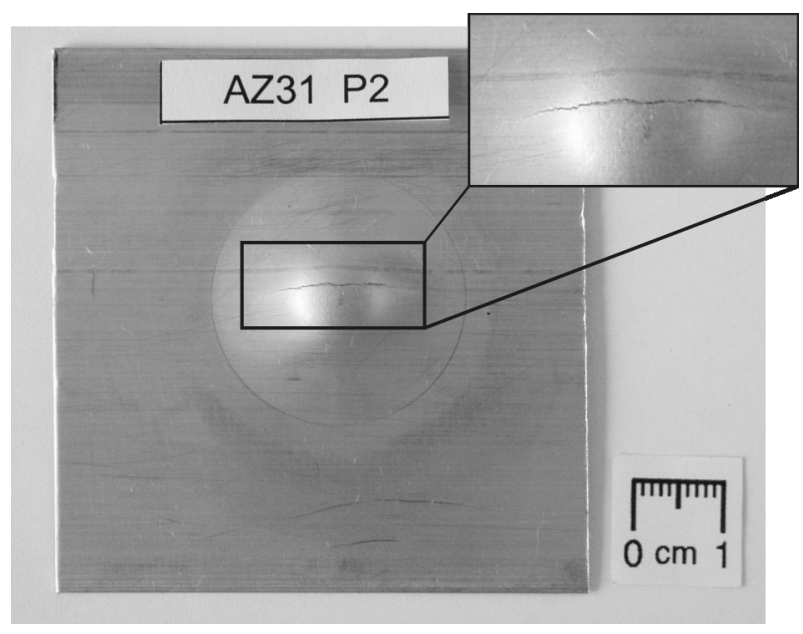

Fig. 53: AZ31 flat profile, tested in the Erichsen cupping test
The formation of splitting cracks, which can be discerned, indicate the existence of pronounced anisotropy in the sheet material.

This is confirmed by the results of the tensile tests which are depicted in Fig. 56. It can be clearly discerned that the tensile strength and the $\mathrm{Rp}_{0.2}$ proof stress increase and the associated fracture strain reduces from the $0^{\circ}$ to the $90^{\circ}$ orientation relative to the extruding direction. 


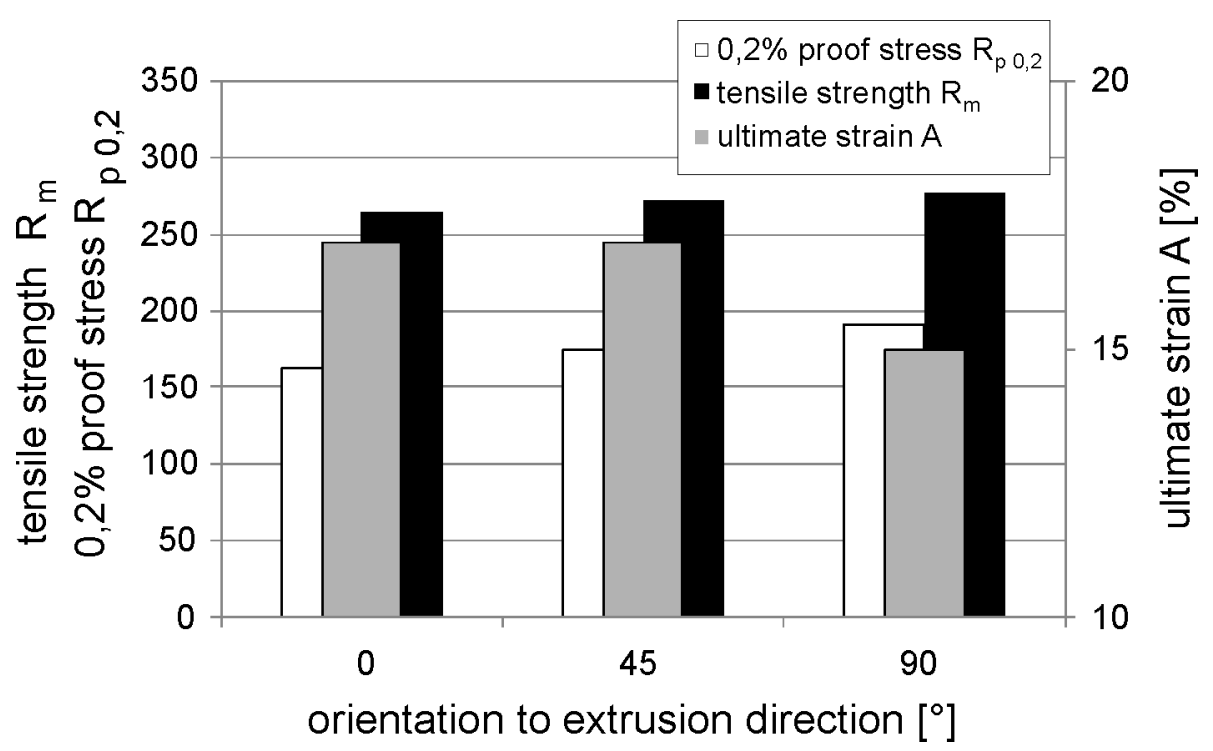

Fig. 54: Tensile strength, proof stress and ultimate strain of extruded flat profiles as a function of orientation to the extruding direction

Initial preliminary tests for profiling these extruded AZ31 strips on the roll forming equipment already showed very good results, see Fig. 57. However, this figure depicts profiled AZ31 slit-tubes which still have wide longitudinal gaps (left) due to the large spring-back in the circumferential direction. On welding the tube's seam, these would lead to high tensile stresses, particularly in the region of the weld seam and thereby impede the sealing of this thin sheeting in the butt joint.

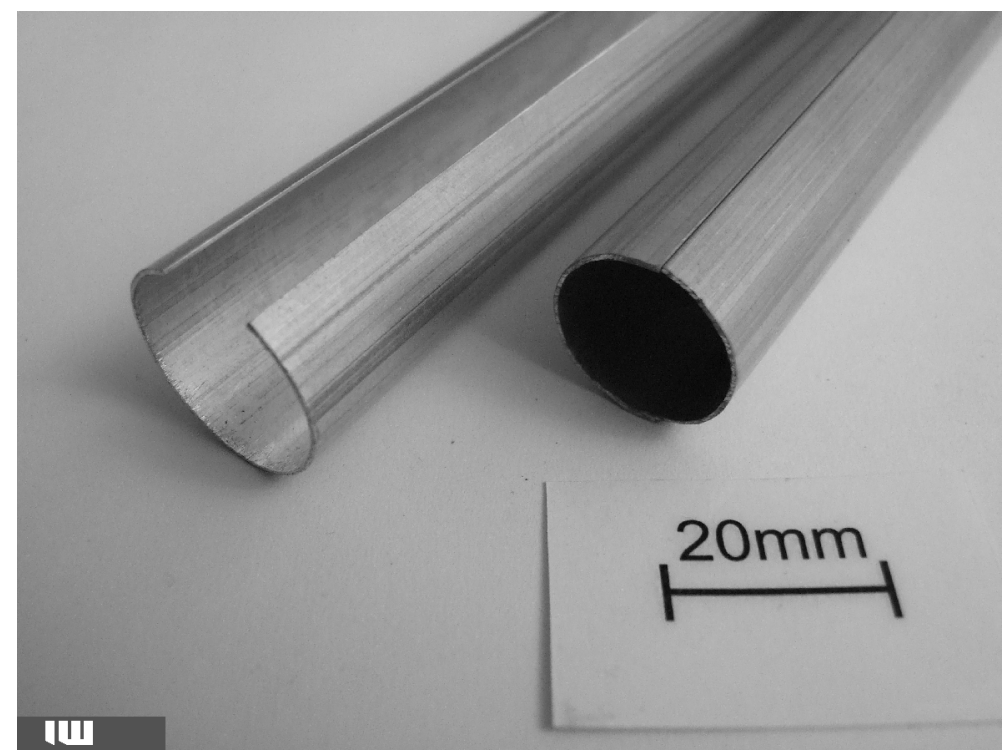

Fig. 55: Roll-formed AZ31 slit-tube, $\varnothing 20 \times 0.5 \mathrm{~mm}$ : left, without heat treatment right, annealed in constrained position for $15 \mathrm{~min}$. at $320^{\circ} \mathrm{C}$

However, by subsequently heat treating (stress relieving) in a constrained position, these stresses can be reduced to the extent that a tube's longitudinal slit is reduced and the tube can be passed the welding process, see Fig. 57 right.

The local foam-reinforcement is to be introduced, as the example depicted in Fig. 58 shows, by the process-integrated foam-filling as well as by employing bonding technologies. 


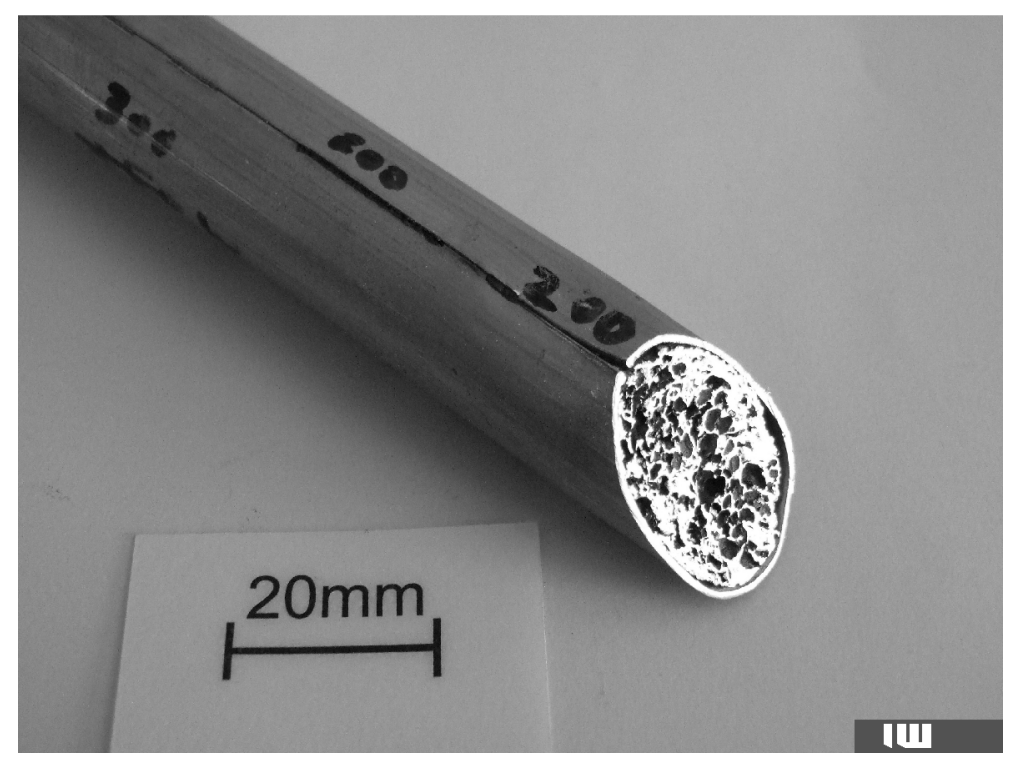

Fig. 56: Homogeneous Mg - Mg-foam composite profile, manufactured from extruded AZ31 flat profile and MgZn3-foam, profile specimen for welding test

\section{Summary}

In the research results from the sub project A4 "Foam filled, rolled, closed profiles of the CRC 675 "Creation of high strength metallic structures and joints by setting up scaled local material properties" explained here, three major themes were explored. The first theme is the enhancement of the powder metallurgical method for manufacturing magnesium foams. By means of employing cold-isostatic pressing (CIP) and subsequently extruding the selected alloys, a significant improvement is obtained in comparison to the current state of research. Heat treated foamable precursor material containing zinc still demonstrate outstanding properties regarding the foam quality. Moreover, it was possible within the framework of the investigations to identify tin as a foam stabiliser so that magnesium alloys containing zinc and tin are investigated for their applications as magnesium foams.

Secondly, due to the low strength of metal foams, an approach is followed to increase this by inserting reinforcements into the foam which have different functioning modes. The reinforcing elements employed were destructively tested to verify their suitability as a reinforcing concept. In particular, it was possible to record significant improvements in the torsional and impact-bending behaviours by means of employing reinforcements. The required impact energy can be increased by a factor of more than 10 for the same density.

Furthermore, to be able to make better use of magnesium foams in profiled lightweight structures, the development of a combined technology is introduced for producing profiles which are locally reinforced with magnesium foam. This technology is characterised by integrating the foaming process into the roll forming process. By using this technology, it was possible to locally foam-fill steel profiles whose damping and bending-strength properties significantly exceeded those of non-reinforced profiles. The bending strength can be raised by a factor of approx. 3 for a moderate weight increase of $23 \%$. Finally, a new technology was introduced for processing ultralight, extruded flat profiles by means of roll forming, to enable locally reinforced homogeneous $\mathrm{Mg}$ - Mg-foam composite profiles to be manufactured in the future. By means of this technology, very precise and extremely light tubular profiles can be produced which must be processed in future research work by using foam-filling and joining technologies. 


\section{Acknowledgements}

The results presented here were acquired within the framework of the Collaborative Research Centre (CRC) 675. The authors would like to thank the German Research Foundation (DFG) for the work's sponsorship.

\section{References}

[1] J. Baumeister et al: Verbundwerkstoffe mit Aluminiumschaum - Anwendungen im Schienenfahrzeugbau. Mat.-wiss und Werkstofftechnik 2007, 38 No.11, pp 939-942

[2] R. Thummler et al: Gefüllte Hohlräume. MM Das Industrie Magazin 36/2006, pp. 108-111

[3] J. Banhart, H.-W. Seeliger: Aluminium Foam Sandwich Panels. Manufacture, Metallurgy and Applications. Advanced Engineering Materials 10, No.9 (2008)

[4] W. Altenhof, A.-M. Harte, R. Turehi: Experimental and numerical compressive testing of aluminium foam filled mild steel tubular hat sections. Proceedings of the 7th International LSDYNA Users Conference, Salzburg (2009), pp. (13)-19-(13)-28

[5] L. Carrino, M. Durante, S. Franchitti: On the Optimization of the Properties of Foam Filled Tubular Structure Using FEM. Proceedings of the International Symposium on Cellular Metals for Structural and Functional Applications, 8-10. Oct. 2008, Dresden (Germany), pp. 336-341

[6] F. Bartl, R. Dallner, M. Hartmann, W. Meyer: Ein numerisches Werkstoffmodell für Mineralschaumverbundwerkstoffe für crashrelevante Anwendungen. Tagungsband Landshuter Leichtbau Kolloquium 2007, Landshut, pp. 81-92

[7] P. Colombo P. (Guest Editor): Special Issue: Highly Porous Metals and Ceramics. Advanced Engineering Materials 10, No. 3 (2008)

[8] L.-P. Lefebvre, J. Banhart, D.C. Dunand (Guest Editors). Special Issue: Metallic Foams. Advanced Engineering Materials 10, No.9 (2008)

[9] T. Hipke, G. Lange, R. Poss: Taschenbuch für Aluminiumschäume. Aluminium Verlag Düsseldorf (2007), ISBN 978-3-87017-258-5

[10]K. Stöbener: Advanced Pore Morphology (APM) - Aluminiumschaum. Fortschritt-Berichte VDI 5 Nr. 727, VDI Verlag (2007)

[11]K. Stöbener, G. Rausch: Aluminium foam-polymer composites: processing and characteristics, in: Journal of Materials Science (2009) 44, pp. 1506-1511

[12]R. Neugebauer et al: Aluminiumschüttherstellung mit schäumbarem Schüttgut und Einfluss der Schüttgeometrie auf grundlegende Eigenschaften von Aluminiumschaum. Aluminium 3/2008, pp. 78-82

[13] J. Haibin, Y. Guang, L. Hongbin: Magnesium foam produced by foaming in melt. Magnesium Technology 2007, TMS, pp. 139-141

[14]C. Körner et al.: Integralschaumgießen von Leichtmetallen. Tagungsband zum Industriekolloquium 2006 des SFB 396, pp. 65-74

[15] M. Hirschmann, C. Körner, R.F. Singer: Integral Foam Moulding - A New Process for Foamed Magnesium Castings. Materials Science Forum Vols. 539-543 (2007), pp. 1827-1832

[16] T. Plorin, D. Bormann, Fr.-W. Bach: The manufacture and characterisation of reinforced magnesium foams. Steel Research, Vol. 79,3 (2008), pp. 185-190 
[17]Fr.-W. Bach, D. Bormann, T. Plorin: Developments for the production of local foamed hollow sections. Advanced Materials Research, Vol. 22 (2007), pp. 37-47, http://www.scientific.net

[18] T. Plorin, D. Bormann, Fr.-W. Bach: Manufacture and characterization of magnesium foams for ultra-lightweight applications. Proceedings Materials Science and Technology (MS\&T) 2009, October 25.-29. 2009, Pittsburgh, Pennsylvania (USA), pp. 2366-2374

[19] N. Grittner, M. Hepke, T. Plorin, C. Biskup, D. Bormann, B. Breidenstein, B.A. Behrens, Fr.W. Bach: Extrusion of slit strips for roll forming. In: Magnesium. 8th International Conference on Magnesium Alloys and their Applications, 26.-29.10.2009, Weimar. Wiley-VCH GmbH \& Co. KGaA, pp. 503-508 